\title{
Understanding the Mechanisms behind the Northward Extension of the West African Monsoon during the Mid-Holocene ${ }^{\mathscr{O}}$
}

\author{
MARCO GAETANI \\ LATMOS/IPSL, UPMC Univ. Paris 06 Sorbonne Universités, UVSQ, CNRS, Paris, France \\ GABRIELE MESSORI \\ Department of Meteorology and Bolin Centre for Climate Research, Stockholm University, Stockholm, Sweden \\ QIONG ZHANG \\ Department of Physical Geography and Bolin Centre for Climate Research, Stockholm University, Stockholm, Sweden \\ CYRILLE FLAMANT \\ LATMOS/IPSL, UPMC Univ. Paris 06 Sorbonne Universités, UVSQ, CNRS, Paris, France \\ FRANCESCO S. R. PAUSATA \\ Department of Meteorology and Bolin Centre for Climate Research, Stockholm University, \\ Stockholm, Sweden, and Department of Earth and Atmospheric Sciences, University of Quebec \\ in Montreal, Montreal, Quebec, Canada
}

(Manuscript received 12 April 2016, in final form 1 June 2017)

\begin{abstract}
Understanding the West African monsoon (WAM) dynamics in the mid-Holocene (MH) is a crucial issue in climate modeling, because numerical models typically fail to reproduce the extensive precipitation suggested by proxy evidence. This discrepancy may be largely due to the assumption of both unrealistic land surface cover and atmospheric aerosol concentration. In this study, the MH environment is simulated in numerical experiments by imposing extensive vegetation over the Sahara and the consequent reduction in airborne dust concentration. A dramatic increase in precipitation is simulated across the whole of West Africa, up to the Mediterranean coast. This precipitation response is in better agreement with proxy data, in comparison with the case in which only changes in orbital forcing are considered. Results show a substantial modification of the monsoonal circulation, characterized by an intensification of large-scale deep convection through the entire Sahara, and a weakening and northward shift $\left(\sim 6.5^{\circ}\right)$ of the African easterly jet. The greening of the Sahara also leads to a substantial reduction in the African easterly wave activity and associated precipitation. The reorganization of the regional atmospheric circulation is driven by the vegetation effect on radiative forcing and associated heat fluxes, with the reduction in dust concentration to enhance this response. The results for the WAM in the MH present important implications for understanding future climate scenarios in the region and in teleconnected areas, in the context of projected wetter conditions in West Africa.
\end{abstract}

Supplemental information related to this paper is available at the Journals Online website: http://dx.doi.org/10.1175/ JCLI-D-16-0299.1.s1.

Corresponding author: Marco Gaetani, marco.gaetani@latmos. ipsl.fr

\section{Introduction}

Understanding climate variability in West Africa is one of the most challenging issues in current climate science, from both the academic and socioeconomic perspectives. Indeed, food security in West African countries is largely based on rain-fed agriculture (IFAD 2013) and is

DOI: 10.1175/JCLI-D-16-0299.1

(C) 2017 American Meteorological Society. For information regarding reuse of this content and general copyright information, consult the AMS Copyright Policy (www.ametsoc.org/PUBSReuseLicenses). 
potentially vulnerable to climate variability (Sultan and Gaetani 2016). Precipitation in West Africa is concentrated in the boreal summer and is primarily associated with the West African monsoon (WAM) (Nicholson 2013). The WAM underwent large variability in the twentieth century, showing a succession of long lasting wet and dry periods following multidecadal trends (Rodríguez-Fonseca et al. 2015). In this context, the need for reliable predictions of rainfall in West Africa on decadal and longer time scales is crucial. However, state-of-the-art climate models are still deficient in correctly reproducing the historical variability and agreeing on future projections (Biasutti 2013). The skill in identifying and disentangling the numerous drivers of the WAM variability that operate at different spatial and temporal scales is modest at best (Biasutti et al. 2009; Rowell 2013).

Furthermore, climate change in West Africa has been much larger during the Holocene interglacial period than in the twentieth century. Extreme droughts, developing in a matter of few years or decades, have been recorded during late Holocene (5-0 kyr BP), with dramatic lake low stands near the equator (Shanahan et al. 2006) and the complete drying of freshwater bodies in the Sahel (Gasse 2000). The opposite scenario occurred during the early Holocene, between 15000 and $5000 \mathrm{yr}$ ago, when increased summer precipitation led to an expansion of the North African lakes and wetlands and an extension of grassland and shrubland into areas that are now desert, giving origin to the so-called Green Sahara or African Humid Period (AHP) (Holmes 2008). Model simulations for the mid-Holocene [MH; 6000 years before the present $(6 \mathrm{kyr} \mathrm{BP})]$ show limitations in reproducing the intensification and geographical expansion of the WAM precipitation (Harrison et al. 2014), and these shortcomings may be similar to those affecting historical simulations and future projections. In general, numerical simulations of the WAM dynamics are particularly sensitive to the shortcomings commonly affecting climate model physics, such as the inaccurate representation of clouds, energy fluxes, coupling at the surface, and convection at the subgrid scale. Moreover, the coarse resolution of global climate models is insufficient to properly simulate the mesoscale convection characterizing the WAM precipitation. In historical simulations, fully coupled models exhibit biases in reproducing the tropical Atlantic dynamics, resulting in warmer sea surface temperatures and weaker monsoonal circulation (Roehrig et al. 2013). In the description of future climate scenarios, the model sensitivity to the global surface warming, and to the direct $\mathrm{CO}_{2}$ radiative forcing, appears crucial for the sign of the projected precipitation trends (Giannini 2010; Gaetani et al. 2016).
A number of studies have addressed the limitations in modeling the West African climate in the MH, pointing to Saharan land cover as the key ingredient to simulate precipitation patterns fitting paleoclimate data. By using a coupled atmosphere-vegetation model, Claussen and Gayler (1997) found an amplification of the response of the atmospheric circulation to changes in Earth's orbit produced by a positive precipitation-vegetation feedback. By prescribing a vegetated Sahara, several authors found a good agreement between simulated precipitation and paleoclimate data, and identified the increased lowlevel moisture, which destabilizes the vertical column and enhances convection, as a crucial factor to maintain the intensification of the monsoon system due to the orbital forcing ( $\mathrm{Su}$ and Neelin 2005; Patricola and Cook 2007; Swann et al. 2014). The use of interactive vegetation climate models confirms the positive precipitationvegetation feedback and the key role of the latent heat increase in favoring the convection (Patricola and Cook 2008; Rachmayani et al. 2015), although the importance of the decrease in surface albedo is also highlighted (Levis et al. 2004). A recent study has shown that accounting for the large reduction in airborne dust emission is also essential for an accurate simulation of the WAM strength during the MH (Pausata et al. 2016). The authors pointed out that the Paleoclimate Modeling Intercomparison Project (PMIP) (Braconnot et al. 2011) and the Coupled Model Intercomparison Project (CMIP) (Taylor et al. 2012) protocols specify the MH dust concentration and land cover to be equal to the preindustrial (PI) period, which may be the main cause of the models' dry bias in simulating the MH WAM. In recent numerical experiments, the inclusion of both dynamic vegetation and dust emissions is not sufficient to reproduce an intensification of the WAM compatible with paleoclimate data, if the initial configuration for the vegetation is set to PI levels. Indeed, the simulated precipitation changes do not allow vegetation to grow north of $15^{\circ} \mathrm{N}$, and the associated variations in dust load compared to PI climate are limited, and so are the feedbacks (Harrison et al. 2015).

Building upon the study of Pausata et al. (2016), this work aims to describe in detail the dynamics of the WAM during the MH, elucidating the mechanisms whereby changes in land cover and associated mineral dust emission alter atmospheric circulation and precipitation patterns. For this purpose, fully coupled climate model experiments, in which Saharan vegetation and dust concentrations are changed concomitantly and in turn are analyzed. In the context of the existing literature on the topic, the analysis of the mineral dust's role in modifying the atmospheric dynamics under vegetated Sahara conditions represents a novel and original contribution to the understanding of the WAM 
TABLE 1. Experimental design used in the control simulation (CTL) and the sensitivity experiments: present-day Sahara and reduced dust (PSRD), Green Sahara and reduced dust (GSRD), and Green Sahara and preindustrial dust (GSPD).

\begin{tabular}{lcclcll}
\hline \hline Simulation & Orbital forcing (yr BP) & GHGs & Vegetation type & Albedo & LAI & Saharan dust \\
\hline CTL & $6 \mathrm{k}$ & MH & Desert & 0.30 & 0 & PI \\
PSRD & $6 \mathrm{k}$ & MH & Desert & 0.30 & 0 & $80 \%$ reduced \\
GSRD & $6 \mathrm{k}$ & MH & Evergreen shrub & 0.15 & 2.6 & $80 \%$ reduced \\
GSPD & $6 \mathrm{k}$ & MH & Evergreen shrub & 0.15 & 2.6 & PI \\
\hline
\end{tabular}

system in the $\mathrm{MH}$. The results of this study are particularly relevant not only from a paleoclimate perspective but also with respect to the assessment of future scenarios for West Africa (Schmidt et al. 2014). Indeed, a number of projections simulate a positive precipitation trend, and a subsequent land greening and dust reduction (Evan et al. 2016). The paper is organized as follows: the climate model and the experimental design are described in section 2, the results are presented and discussed in section 3 , and the main findings are summarized in section 4 .

\section{Model and experimental setup}

In the present study, the climate simulations performed by Pausata et al. (2016), using version 3.1 of the atmosphere-ocean fully coupled climate model EC-Earth (Hazeleger et al. 2010), are analyzed. The atmospheric model is based on the Integrated Forecast System (IFS cycle 36r4) (https://www.ecmwf.int/en/ forecasts/documentation-and-support), including the H-TESSEL land model [see details in van den Hurk et al. (2000)]. In the land model, each grid box is divided into fractions (bare ground, low and high vegetation, intercepted water, shaded and exposed snow are represented over land), with properties defining separate heat and water fluxes used in an energy balance equation solved for the skin temperature. A fraction of the rainfall is collected by an interception layer, where the remaining fraction is partitioned between surface runoff and infiltration. Infiltration and runoff schemes depend on the soil texture and standard deviation of orography. The simulation is run at T159 horizontal spectral resolution $\left(\sim 1.125^{\circ}\right.$, approximately $\left.125 \mathrm{~km}\right)$ with 62 vertical levels. The atmospheric component is coupled by the OASIS 3 coupler (Valcke 2006) to the Nucleus for European Modeling of the Ocean (NEMO) version 2 (Madec 2008), and the Louvain-la-Neuve Sea Ice Model version 3 (LIM3) (Vancoppenolle et al. 2009). The ocean component NEMO has a nominal horizontal resolution of $1^{\circ}$ and 46 vertical levels.

A control simulation (CTL) is performed following the PMIP3 protocol (Braconnot et al. 2011). The orbital forcing is set to $\mathrm{MH}$ values (6 kyr BP). For the greenhouse gases, the methane is set at $650 \mathrm{ppb}$, instead of the
PI value of $760 \mathrm{ppb}$, and $\mathrm{CO}_{2}$ and other greenhouse gases are set to PI levels. Aerosol particle emissions, the solar constant, ice sheets, topography, and coastlines are set to PI conditions. The CTL run is compared to three sensitivity experiments, which simulate the $\mathrm{MH}$ climate in the presence of a Green Sahara with reduced atmospheric dust concentrations (GSRD), a Green Sahara with PI dust (GSPD), and a present-day Sahara with reduced dust (PSRD).

The changes in vegetation in the GSRD and GSPD experiments are imposed by prescribing the vegetation type over the Sahara-Sahel region $\left(11^{\circ}-33^{\circ} \mathrm{N}, 15^{\circ} \mathrm{W}-\right.$ $35^{\circ} \mathrm{E}$ ) to be evergreen shrub with a leaf area index (LAI) equal to 2.6. The change in vegetation cover leads to a decrease in the albedo (averaged into the Sahara-Sahel region) from 0.30 to 0.15 (Table 1 ). Surface roughness and soil wetness are prescribed to PI values in the sensitivity experiments. As discussed in detail in Pausata et al. (2016), the experiment design is idealized. Nevertheless, recent studies have shown that paleolakes extended at least to $28^{\circ} \mathrm{N}$ (Lézine et al. 2011) and tropical vegetation migrated as far as $24^{\circ} \mathrm{N}$ during the AHP, about $1000 \mathrm{~km}$ farther north than today (Hély et al. 2014). Based on leaf wax isotopes, Tierney et al. (2017) show that the Green Sahara extended all the way to the northernmost part of the western Sahara, with peaks in precipitation above $1000 \mathrm{~mm} \mathrm{yr}^{-1}$ relative to present day. Hence, proxy evidence suggests an extensive greening across the entire Sahara during the MH, overall supporting the choice of the prescribed vegetation cover in the GSRD and GSPD experiments. Furthermore, Pausata et al. (2016) have shown that changes in WAM strength do not strongly depend on the exact choice of the vegetation type prescribed over eastern Sahara, which may have experienced dryer conditions compared to the western part.

The atmospheric dust concentration is prescribed in the CTL simulation by using the PI dust climatology derived from the Community Atmosphere Model (Albani et al. 2014), which is used in the CMIP5 exercise. The size distribution of dust corresponds to diameter ranges from 0.1 to $10.0 \mu \mathrm{m}$. The model used in this study simulates the direct effect of dust on the atmospheric radiative balance, while the indirect effect on cloud formation and microphysics is not included. 
Prelndustrial

a) JJAS Dust Mixing Ratio $\left[10^{-6} \mathrm{~kg} / \mathrm{kg}\right]$
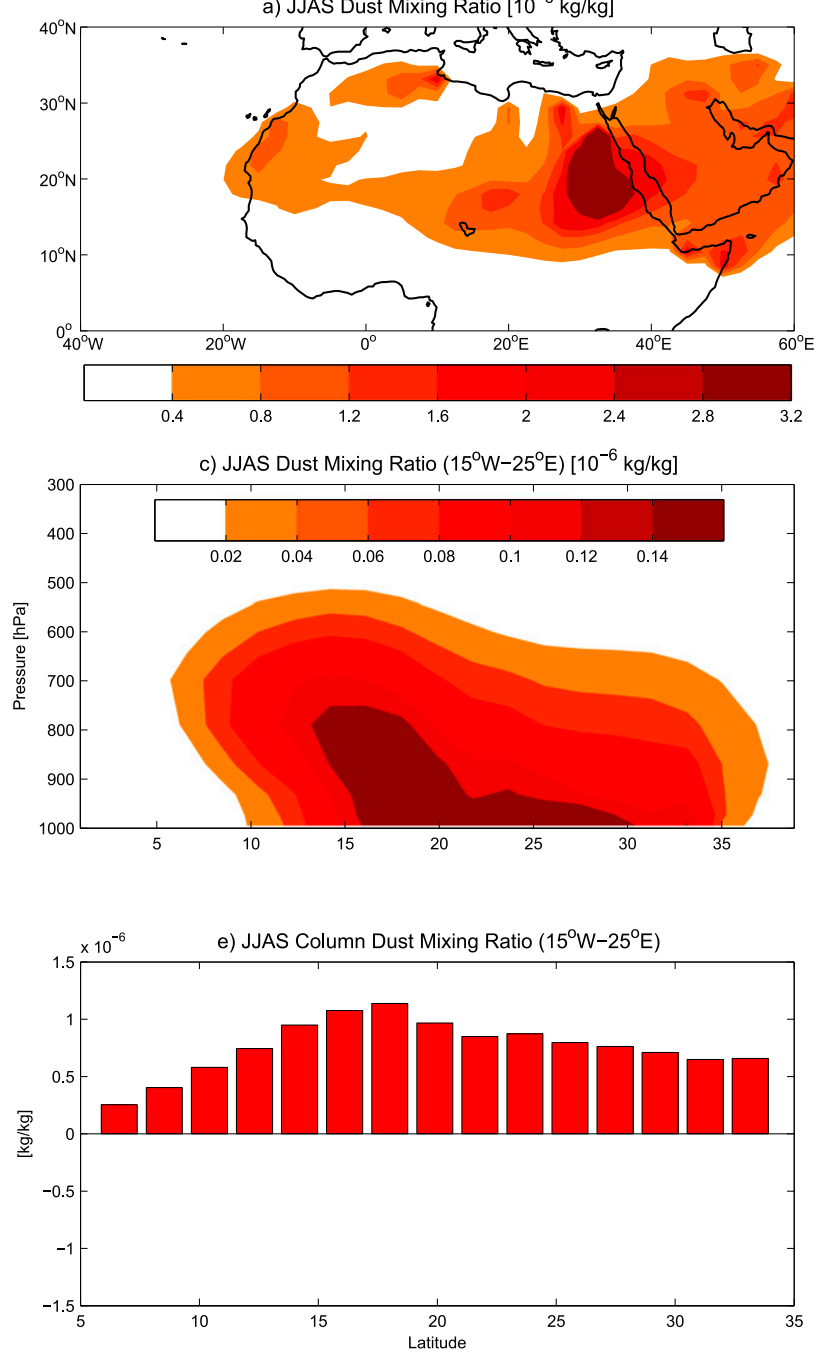

Reduced Dust - Prelndustrial

b) JJAS Dust Mixing Ratio $\left[10^{-6} \mathrm{~kg} / \mathrm{kg}\right]$

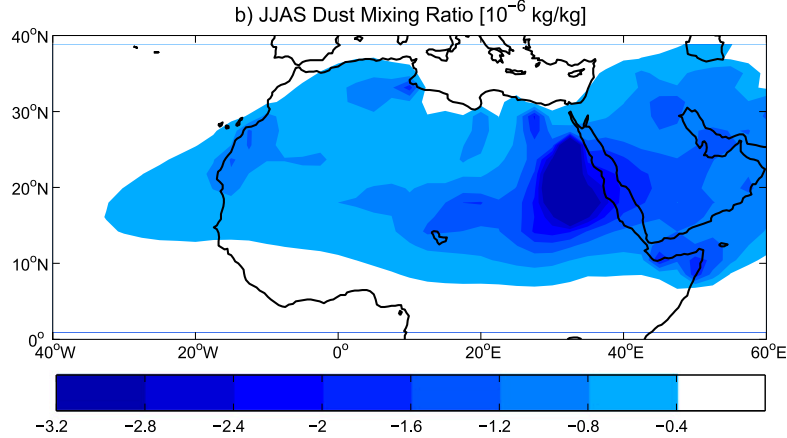

d) JJAS Dust Mixing Ratio $\left(15^{\circ} \mathrm{W}-25^{\circ} \mathrm{E}\right)\left[10^{-6} \mathrm{~kg} / \mathrm{kg}\right]$
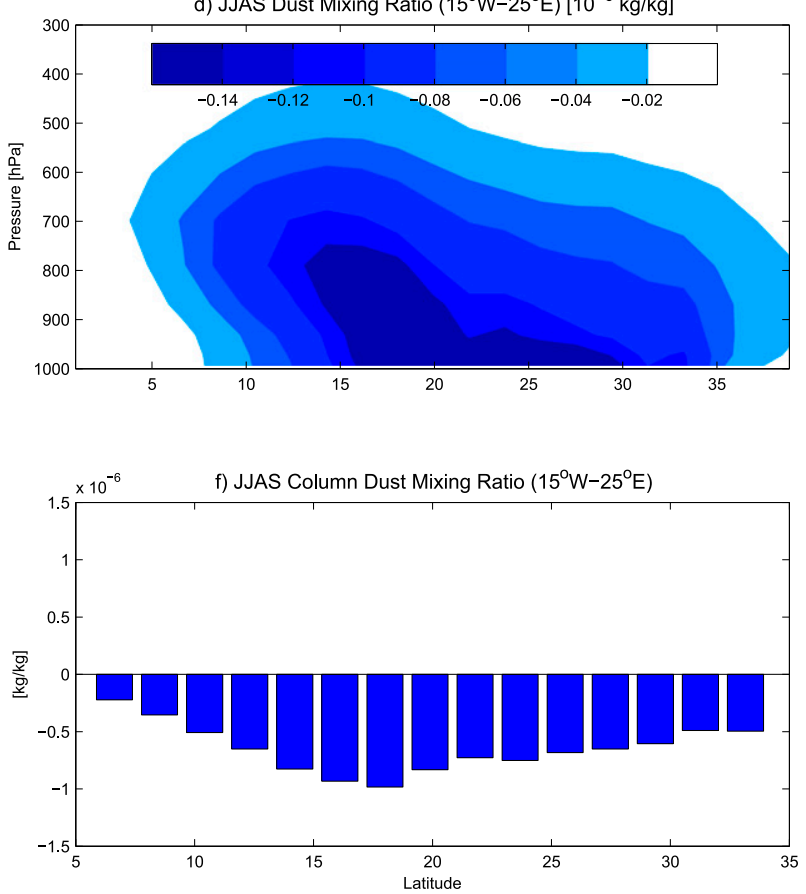

FIG. 1. (left) JJAS preindustrial dust mixing ratio $\left(\mathrm{kg} \mathrm{kg}^{-1}\right)$, prescribed in the CTL and GSPD simulations, and (right) difference between reduced dust and preindustrial concentration. (a),(b) Column integral, (c),(d) vertical profile averaged in the range $\left[15^{\circ} \mathrm{W}-25^{\circ} \mathrm{E}\right]$, and (e),(f) meridional profile of the column integral.

To take into account the decreased dust emission and concentration typical of the AHP, in the GSRD and PSRD experiments the PI dust concentration is reduced by $80 \%$ throughout the troposphere (up to $150 \mathrm{hPa}$ ) over a broad area around the Sahara desert [see Fig. S1 in Pausata et al. (2016)]. This choice is justified by evidence from proxy records off the coast of Morocco showing a dust flux reduction of $60 \%-80 \%$ (deMenocal et al. 2000; McGee et al. 2013) and also supported by a recent dust modeling study (Egerer et al. 2016). The imposed dust reduction leads to a decrease in the global dust aerosol optical depth (AOD) of almost $60 \%$ and in the total AOD of 0.02 [see Fig. 1 in Pausata et al. (2016)]. The PI climatological dust mixing ratio prescribed in the CTL and GSPD simulations (Fig. 1a) closely represents the main features of the present-day dust distribution over North Africa, namely the peak over the Bodélé depression north of Lake Chad, and the band over western Sahara and Sahel (Ginoux et al. 2012). An intense peak in concentration is present over eastern Sahara, largely dominating the African dust emission in summer, which appears as an artifact when compared with satellite retrievals for the present-day distribution [cf. Fig. 1a herein with Fig. 4 in Ginoux et al. (2012)]. This artifact affects the radiative balance simulated in the region by masking the dust sources to the west, with potential repercussions on the simulation of the regional atmospheric dynamics. Additional simulations have been performed 
to test the effect of imposing a more realistic dust climatology, finding barely significant differences in the effect of dust reduction on precipitation (see Figs. S1-S3 in the online supplemental material). However, dust emission from the central and western Sahara is intimately linked to the surface wind pattern over North Africa, which shows a broad variability at multidecadal time scales (Evan et al. 2016). Thus, substantial differences in the surface wind fields in the PI period could explain this apparently incongruous dust concentration pattern produced by the CAM model. However, the meridional profile of dust concentration (averaged between $15^{\circ} \mathrm{W}$ and $25^{\circ} \mathrm{E}$, to cut off the unusual peak to the east) is close to the present-day pattern, showing a dust layer reaching the midtroposphere, with an intense peak around $15^{\circ}-$ $20^{\circ} \mathrm{N}$ (corresponding to the Bodélé and western Sahara sources), and a midtropospheric plume extending south to the Gulf of Guinea (Figs. 1c,e). When the dust concentration is reduced by $80 \%$, the highest anomalies are located where the PI concentration is maximum, namely over the central and eastern Sahara, around $15^{\circ}-20^{\circ} \mathrm{N}$, up to $800-700 \mathrm{hPa}$ (Figs. 1b,d,f).

In each experiment, initial conditions are taken from a 700-yr PI spinup run, and the simulations are then run for about 300 years. The quasi-equilibrium is reached after 100-200 years depending on the experiment. This study focuses on the monsoonal season [June-September (JJAS)] for the last 30 years of each experiment. The experimental setup is summarized in Table 1, and a detailed description is presented in Pausata et al. (2016), along with a more comprehensive discussion of the model's performances.

\section{Results}

This section presents the impacts of changes in Saharan vegetation and dust concentration on precipitation and atmospheric dynamics over West Africa in each sensitivity experiment relative to the $\mathrm{MH}$ reference simulation (CTL). The responses in the radiative and energy variables are then analyzed. Unless otherwise specified, the significance of the changes is estimated via a two-tailed Student's $t$ test at the $95 \%$ confidence level.

\section{a. Precipitation and dynamics}

In the CTL simulation (Fig. 2a), the climatological WAM precipitation is consistent with the "classical" pattern observed in the PI and historical periods (Nicholson 2013). The peak precipitation reaches over $16 \mathrm{~mm} \mathrm{day}^{-1}$ on the western coastline around $10^{\circ} \mathrm{N}$, and approximately $10 \mathrm{~mm} \mathrm{day}^{-1}$ in the interior, slightly in excess of present-day observations (not shown) but in agreement with the most CMIP5 models (Harrison et al. 2014).
The northernmost extent of the monsoon is just above $16^{\circ} \mathrm{N}, 2^{\circ}$ latitude farther north than a PI simulation performed using the same model [see Fig. S6 in Pausata et al. (2016)]. The main change in the precipitation pattern in the GSRD experiment is a dramatic increase of precipitation over the whole North African subcontinent, with significant anomalies spanning $10^{\circ}$ to $25^{\circ} \mathrm{N}$ and extending to the Mediterranean coast in the western sector (Figs. 2b,c). The response in the GSPD experiment (Figs. 2d,e) is qualitatively similar to the GSRD experiment, though slightly weaker in intensity and extension, suggesting that the dust reduction tends to enhance the vegetation forcing (see the GSRD-GSPD difference in Fig. 2h). In the Green Sahara experiments, the location of the precipitation maximum is around $15^{\circ} \mathrm{N}$ (Fig. $2 \mathrm{~b}, \mathrm{~d}$ ), consistent with the proxy-based estimation by Hély et al. (2014). The simulated yearly precipitation anomalies exceed $700 \mathrm{~mm}$ around the peak $\left(10^{\circ}-20^{\circ} \mathrm{N}\right)$ and reach $300 \mathrm{~mm}$ in the Sahara region $\left(20^{\circ}-30^{\circ} \mathrm{N}\right)$. Skinner and Poulsen (2016) find similar precipitation anomalies extending into the late monsoonal season, pointing out the role of extratropical troughs advecting tropical moisture toward the Sahara in the form of concentrated plumes of water vapor. These values are in line with $\mathrm{MH}$ precipitation reconstructions based on diverse paleoclimate proxies, which estimate the difference from the present day over West Africa to be in the range of $300-500 \mathrm{~mm}$ (Kröpelin et al. 2008; Harrison et al. 2014; Tierney et al. 2017). On the other hand, the reduction of dust alone in the PSRD experiment leads to reduced precipitation over the Sahelian belt relative to the CTL case (Figs. 2f,g).

The wind pattern at $925 \mathrm{hPa}$ in the CTL simulation is dominated by the southwesterly moist monsoonal flow from the tropical Atlantic, the northeasterly Harmattan dry wind, and the cyclonic gyre associated with the Saharan heat low (SHL; Lavaysse et al. 2009), located around $\left[20^{\circ}-30^{\circ} \mathrm{N}, 10^{\circ} \mathrm{W}-10^{\circ} \mathrm{E}\right]$ (Fig. 3a). In the GSRD experiment (Fig. 3b), the mean wind pattern displays a general northward shift, relative to the MH CTL simulation, resulting in an intensification of the monsoonal flow and a weakening of the Harmattan wind and the SHL ( $-2.1 \mathrm{~K}$ at the peak). The latter migrates $3.2^{\circ}$ to the north (Fig. 3c), coherent with the precipitation response shown in Figs. $2 b$ and $2 c$. In comparison to the GSRD experiment, the GSPD experiment shows a similar response in the wind field (Fig. 3h), with a slightly stronger SHL $\left(+0.9 \mathrm{~K}\right.$ at the peak), displaced $0.7^{\circ}$ to the south (Figs. 3d,e). The negative precipitation response in the Sahel simulated in the PSRD experiment (Figs. 2f,g) is instead associated with a weakening of the monsoonal flow and a deeper southward penetration of the Harmattan in the eastern Sahel, accompanied by a $0.7^{\circ}$ southward migration of the SHL (Figs. 3f,g). 
a) MH CTL JJAS | precipitation [mm/day]

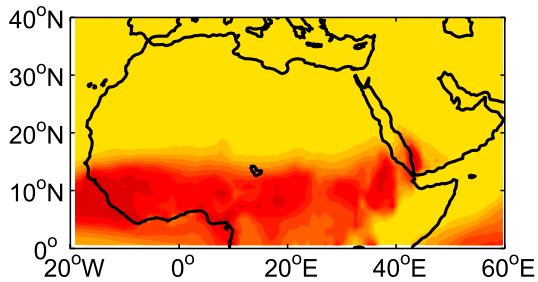

b) GSRD

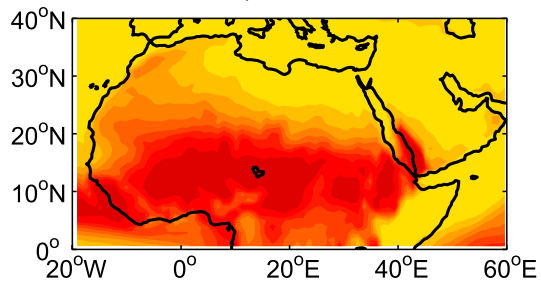

d) GSPD

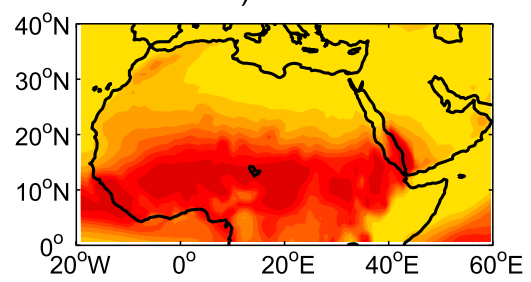

f) PSRD

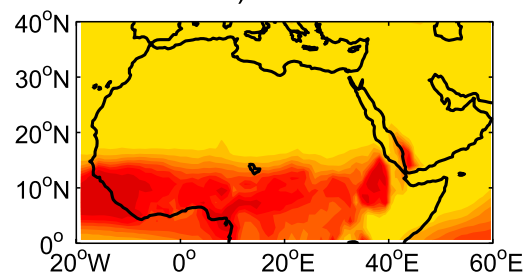

c) GSRD - CTL

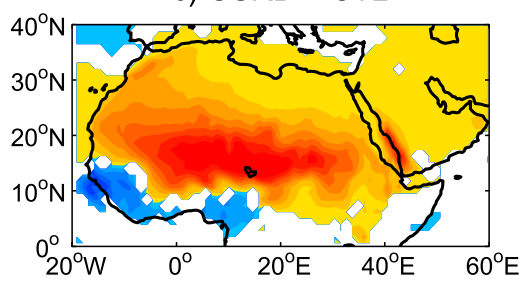

e) GSPD - CTL

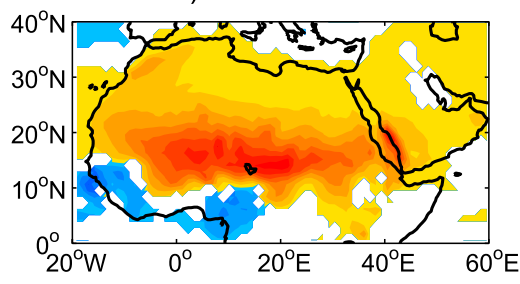

g) PSRD - CTL

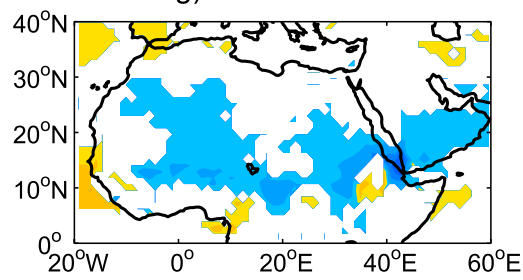

h) GSRD - GSPD

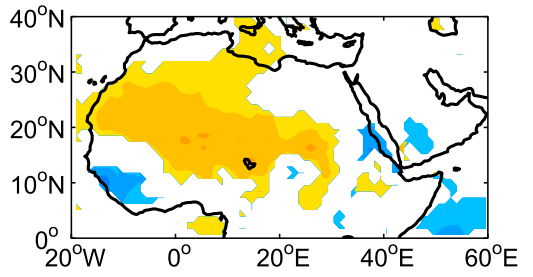

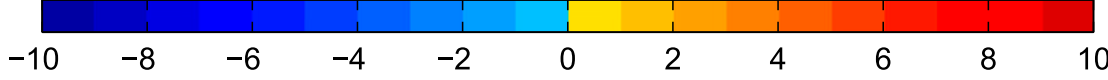

FIG. 2. JJAS precipitation $\left(\mathrm{mm} \mathrm{day}^{-1}\right)$ : (a),(b),(d),(f) climatological means for the CTL simulation and the sensitivity experiments, and (c),(e),(g) differences between the sensitivity experiments and the CTL simulation. (h) The difference between the GSRD and GSPD experiments. Significance at $95 \%$ confidence level is displayed. 
a) MH CTL JJAS | T850 \& wind925

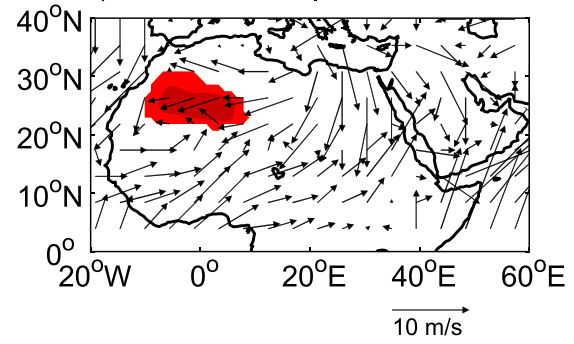

b) GSRD

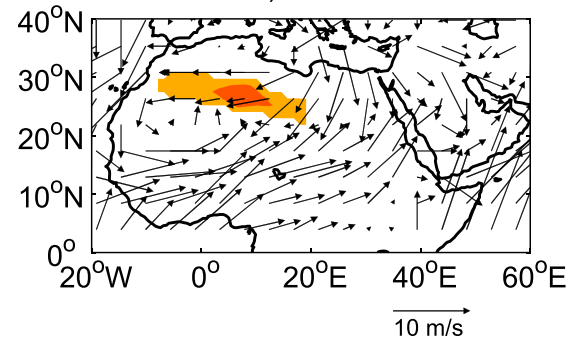

d) GSPD

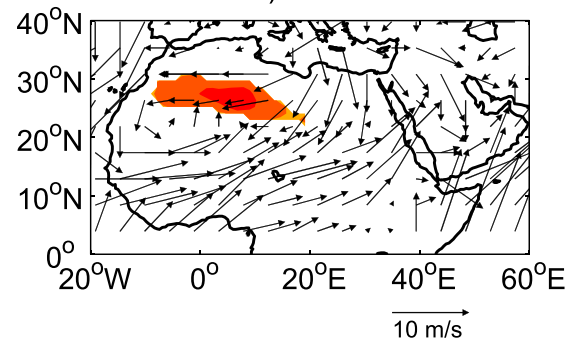

f) PSRD
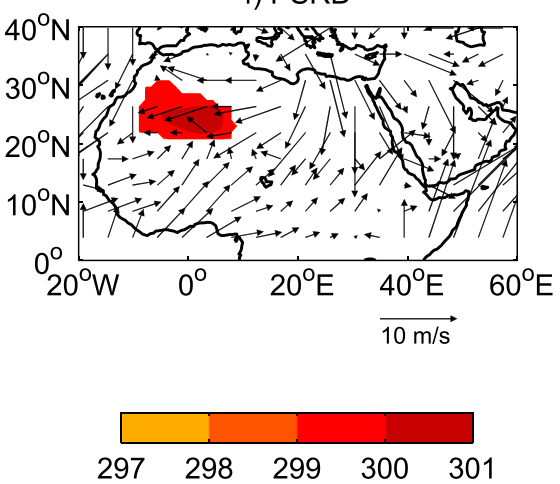

c) GSRD-CTL

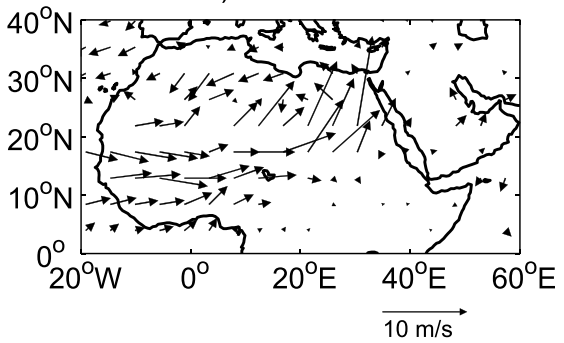

e) GSPD-CTL

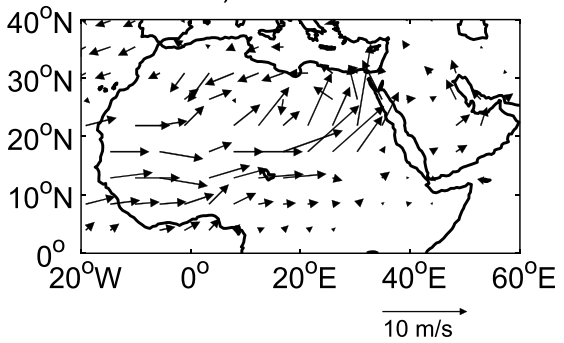

g) PSRD-CTL

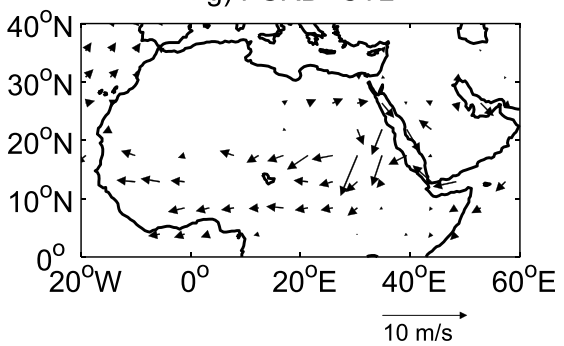

h) GSRD-GSPD

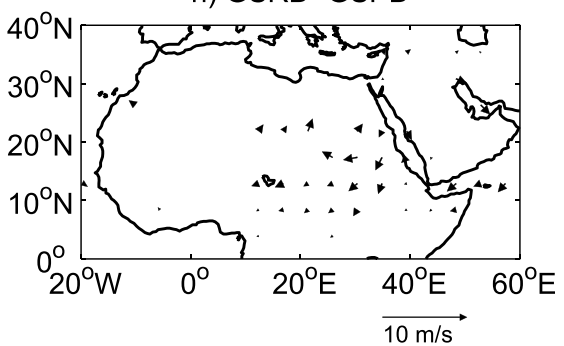

FIG. 3. JJAS wind field at $925 \mathrm{hPa}\left(\mathrm{m} \mathrm{s}^{-1}\right)$ : (a),(b),(d),(f) climatological means for the CTL simulation and the sensitivity experiments, and (c),(e),(g) differences between the sensitivity experiments and the CTL simulation. (h) The difference between the GSRD and GSPD experiments. Significance at $95 \%$ confidence level is displayed. Shadings indicate the Saharan heat low location and intensity, represented through the values of air temperature at $850 \mathrm{hPa}(\mathrm{K})$ exceeding the 90th percentile in the domain $\left[0^{\circ}-40^{\circ} \mathrm{N}, 20^{\circ} \mathrm{W}-20^{\circ} \mathrm{E}\right]$ (Lavaysse et al. 2009). The SHL position and intensity is determined by detecting the maximum of the air temperature at $850 \mathrm{hPa}$ inside the domain. 
In the CTL simulation, the midtropospheric $(700 \mathrm{hPa})$ wind field appears similar, in its main features, to the circulation pattern characterizing the present-day WAM (Fig. 4a). The African easterly jet (AEJ) axis is located around $16^{\circ} \mathrm{N}$, and the anticyclonic gyre of the Saharan high contrasts the SHL in the lower troposphere (Chen 2005). The GSRD experiment shows a dramatic reorganization of the circulation, with a significant $6.5^{\circ}$ northward shift and $2.7 \mathrm{~m} \mathrm{~s}^{-1}$ weakening of the AEJ, and the installation of a westerly flow around $10^{\circ}-15^{\circ} \mathrm{N}$. This results in a large-scale cyclonic gyre over West Africa around $15^{\circ} \mathrm{N}$, and a substantial weakening of the Saharan high (Figs. 4b,c). The wind field response in the GSPD experiment shows a similar structure in comparison with the GSRD experiment, but in this case the Saharan high is slightly stronger and the AEJ is slightly weaker and displaced $1.2^{\circ}$ to the south (Figs. $4 \mathrm{~d}, \mathrm{e}, \mathrm{h}$ ). In present-day atmospheric dynamics, the AEJ is maintained by the soil moisture gradient at the surface and the two meridional circulations forced by the dry convection of the SHL to the north and the moist convection associated with the intertropical convergence zone (ITCZ) to the south (Thorncroft and Blackburn 1999; Wu et al. 2009). Therefore, the weakening and northward shift of the jet in the Green Sahara scenario is the expected response to the vanished surface soil moisture gradient and the substantial reduction of the SHL-associated circulation. In the PSRD experiment, the only significant change is a $1.5^{\circ}$ southward shift of the AEJ compared to CTL (Figs. 4f,g). Very similar response patterns are observed at $500 \mathrm{hPa}$ (Fig. S4), pointing to the emergence of an intense westerly flow around $10^{\circ} \mathrm{N}$ from low levels up to the midtroposphere, and a remarkable limitation in the southward extension of the Saharan high in the GSRD and GSPD experiments.

The upper tropospheric circulation at $200 \mathrm{hPa}$ is dominated by the tropical easterly jet (TEJ) axis between 0 and $15^{\circ} \mathrm{N}$ over Africa, the subtropical jet from the Mediterranean Sea to midlatitudes in western Asia, and the subpolar jet at midlatitudes over the North Atlantic (Fig. 5a). The GSRD and GSPD experiments (Figs. 5b-e) show a general intensification of the zonal circulation in the upper troposphere, characterized by a northward shift of the subtropical jet and the emergence of an easterly jet streak around $15^{\circ} \mathrm{N}$ over West Africa. The responses in GSRD and GSPD are not significantly different (Figs. 5c,e,h). The response of the zonal circulation in the upper troposphere to the greening of the Sahara is interpreted as the upper branch of an anomalous Walker-like circulation (Fig. S5), generated by the widespread intensification of deep convection, and connected with the strengthened westerly flow in the lower troposphere (see Figs. 3c,e). In the PSRD experiment, the zonal circulation is weakened and shifted slightly southward (Figs. 5f,g).

The dramatic reorganization of the regional circulation in the GSRD experiment is also revealed by the meridional overturning circulation averaged over West Africa $\left(10^{\circ} \mathrm{W}-10^{\circ} \mathrm{E}\right)$ (Fig. 6). The CTL experiment simulates a circulation pattern resembling the largescale dynamics associated with the present-day WAM (Fig. 6a): 1) the Southern Hemisphere Hadley cell, 2) the southerly monsoonal flow in the lower troposphere reaching the Sahel, 3) the deep convection associated with the ITCZ, and 4) the dry shallow convection over the Sahara associated with the SHL, contrasting with the subsidence associated with the Saharan high in the midtroposphere (500-600 hPa) (Nicholson 2013). In the GSRD and GSPD experiments, the change in surface conditions over the Sahara leads to an extension of the deep convection up to $30^{\circ}-35^{\circ} \mathrm{N}$, which cancels the midtropospheric divergence associated with the SHL shallow convection contrasting the Saharan high subsidence (Figs. 6b,d). The reduction in dust concentration amplifies the response to the land cover change, inducing stronger anomalies in deep convection over the Sahel and the Sahara desert (Figs. 6c,e,h). The PSRD experiment does not show any substantial systematic changes in the atmospheric meridional overturning circulation compared to the CTL experiment (Figs. 6f,g).

The analysis discussed above shows that a greening of the Sahara has a dramatic impact on West African precipitation, introducing unusual features in the monsoonrelated regional circulation. Summarizing, rainfall intensifies over the Sahara and extends all the way up to the Mediterranean coast (Fig. 2), and some of the dynamical features characterizing the classical WAM picture are substantially altered. The monsoonal flow extends far to the north and into the midtroposphere, weakening the AEJ and shifting it northward by $6.5^{\circ}$ (Figs. 3 and 4). Moreover, the midtropospheric contrast between the SHL convection and the Saharan high subsidence vanishes (Figs. 3 and 4). These changes appear as a general reorganization of the circulation toward a cyclonic gyre throughout the troposphere, resulting from the development of deep convection over the Sahara (Fig. 6). Patricola and Cook (2007) described similar modifications to the monsoonal dynamics during the $\mathrm{MH}$, by prescribing shrubland north of approximately $20^{\circ}$ in regional climate model simulations. The present study highlights that the reduction in dust concentration, following the greening of the Sahara, amplifies the impact of land cover change. On the other hand, the effect of reduction in dust alone results in a weak decrease in the Sahelian precipitation, accompanied by small changes in the atmospheric circulation. This suggests a peculiar role 
a) MH CTL JJAS | Z700 \& wind 700

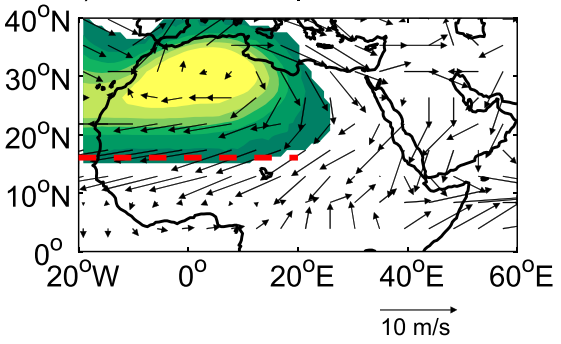

b) GSRD

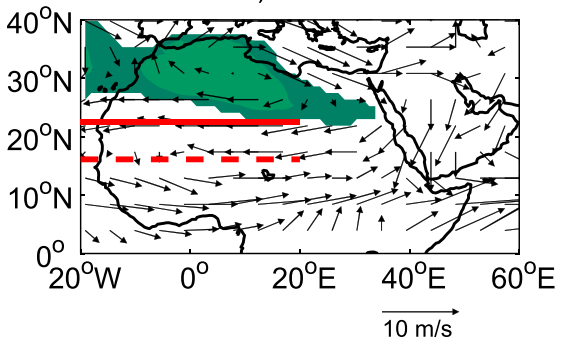

d) GSPD

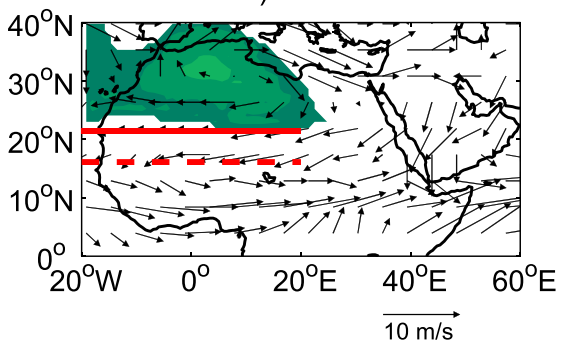

f) PSRD
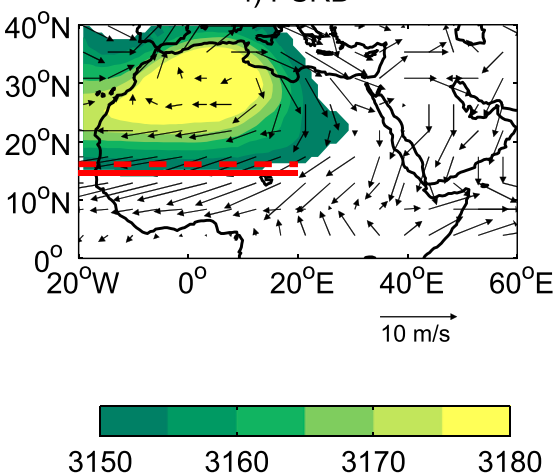

c) GSRD-CTL

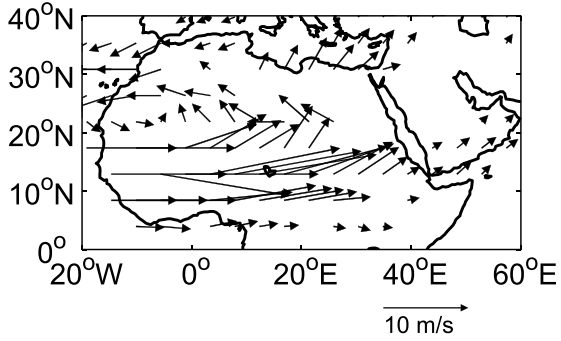

e) GSPD-CTL

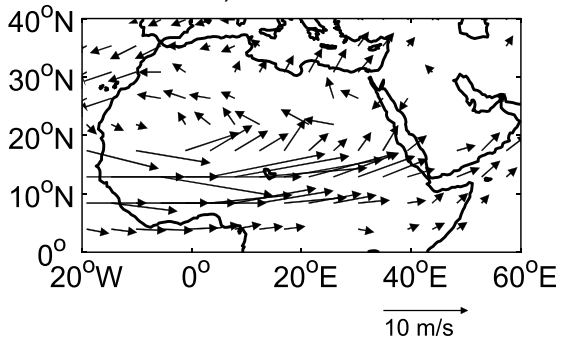

g) PSRD-CTL

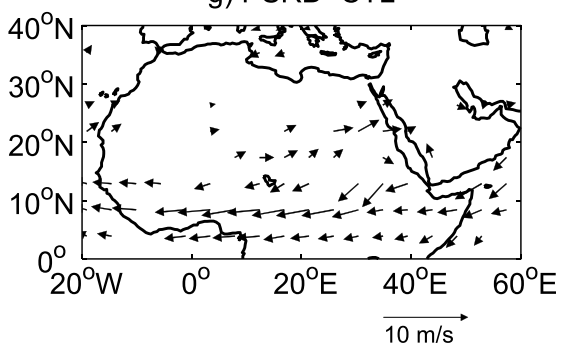

h) GSRD-GSPD

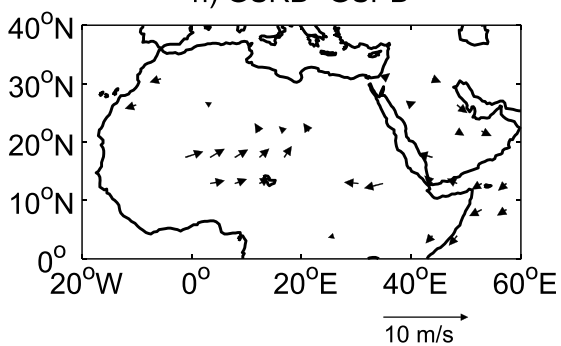

FIG. 4. As in Fig. 3, but at $700 \mathrm{hPa}$. Shadings indicate the Saharan high location and intensity, represented through the geopotential height at $700 \mathrm{hPa}$ exceeding $3150 \mathrm{~m}$. Red lines represent the mean positions of the African easterly jet in the CTL simulation (dashed) and the sensitivity experiments (solid). The mean axis of the African easterly jet is determined in the domain $\left[20^{\circ} \mathrm{W}-20^{\circ} \mathrm{E}, 0^{\circ}-40^{\circ} \mathrm{N}\right]$ by detecting, at each longitude, the latitudinal location of the minimum of the zonal wind at $700 \mathrm{hPa}$, and averaging along the zonal direction. 
a) MH CTL JJAS | zonal wind 200

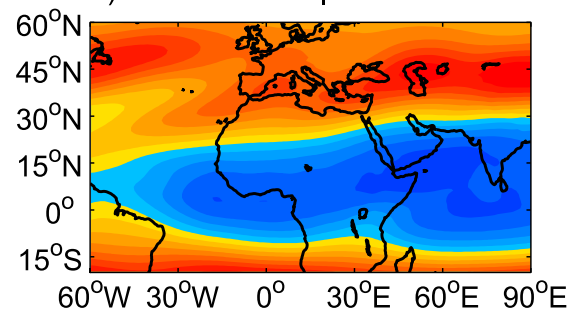

b) GSRD

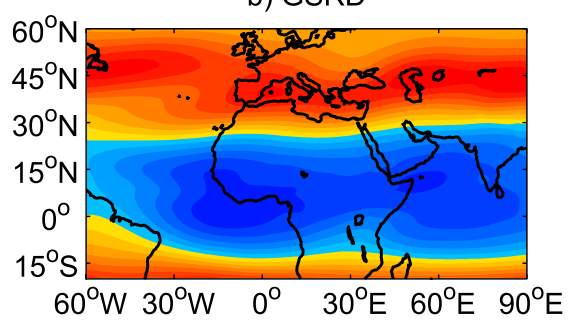

d) GSPD

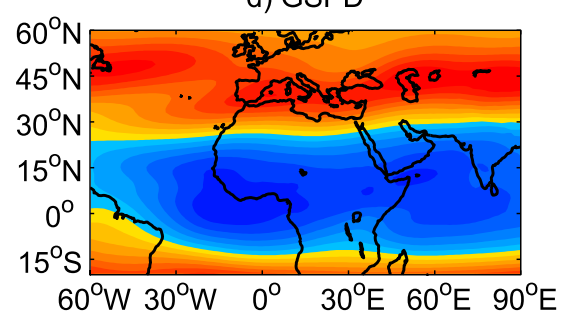

f) PSRD

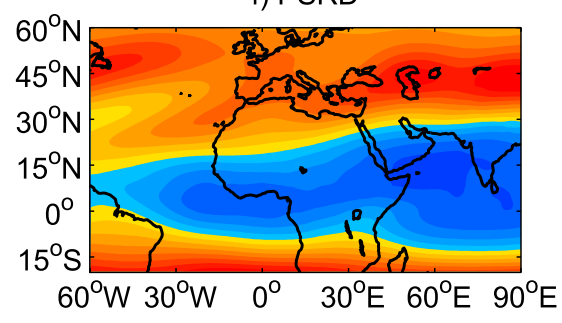

$60^{\circ} \mathrm{W} 30^{\circ} \mathrm{W} \quad 0^{\circ} \quad 30^{\circ} \mathrm{E} \quad 60^{\circ} \mathrm{E} \quad 90^{\circ} \mathrm{E}$

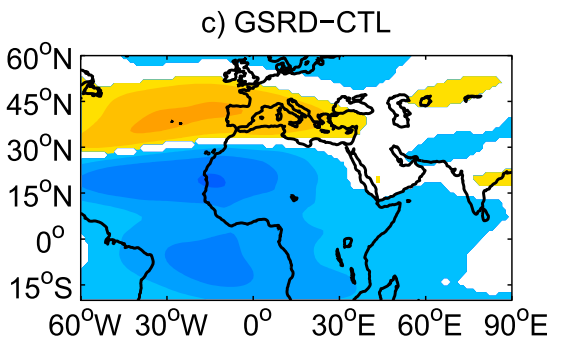

e) GSPD-CTL

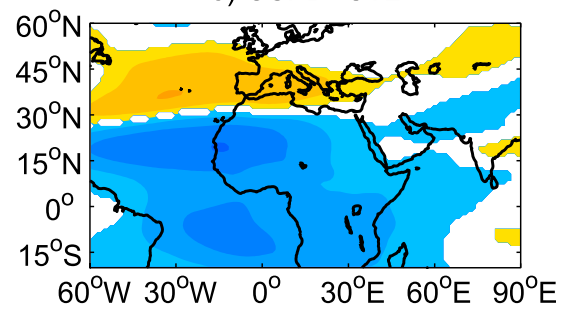

g) PSRD-CTL

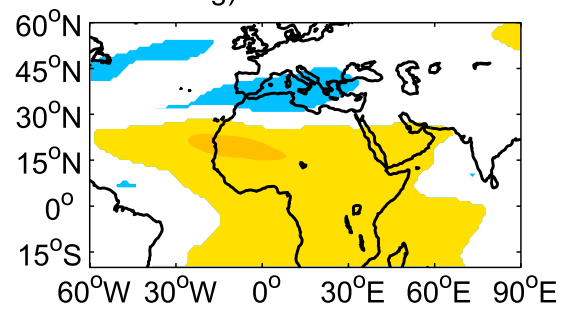

h) GSRD-GSPD

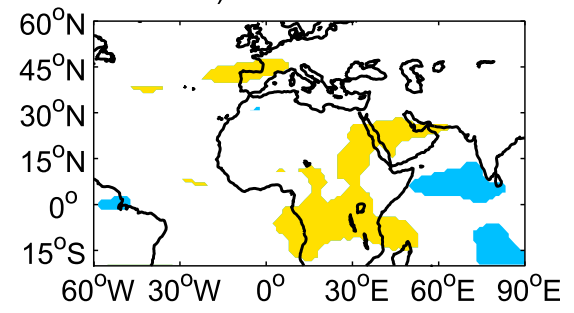

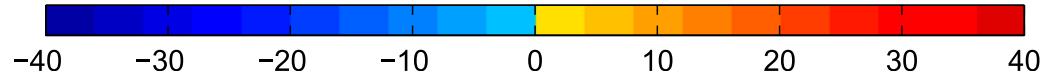

FIG. 5. JJAS wind field at $200 \mathrm{hPa}\left(\mathrm{m} \mathrm{s}^{-1}\right)$ : (a),(b),(d),(f) climatological means for the CTL simulation and the sensitivity experiments, and (c),(e),(g) differences between the sensitivity experiments and the CTL simulation. (h) The difference between the GSRD and GSPD experiments. Significance at $95 \%$ confidence level is displayed. 
a) MH JJAS CTL (v,-omega) $10^{\circ} \mathrm{W}-10^{\circ} \mathrm{E}$

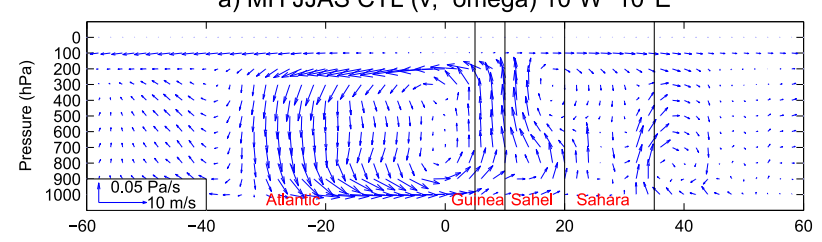

b) GSRD

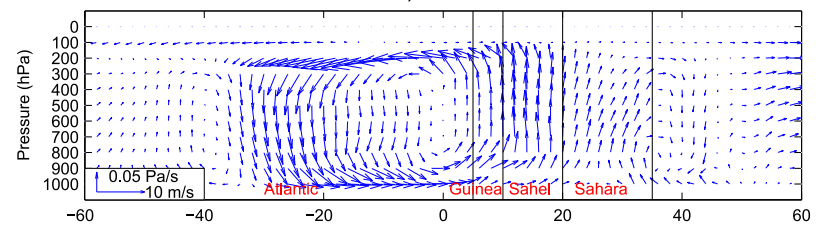

d) GSPD

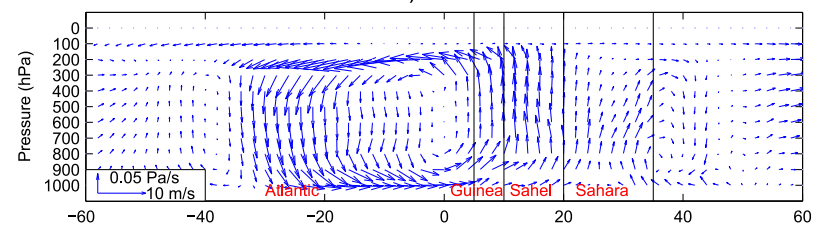

f) PSRD
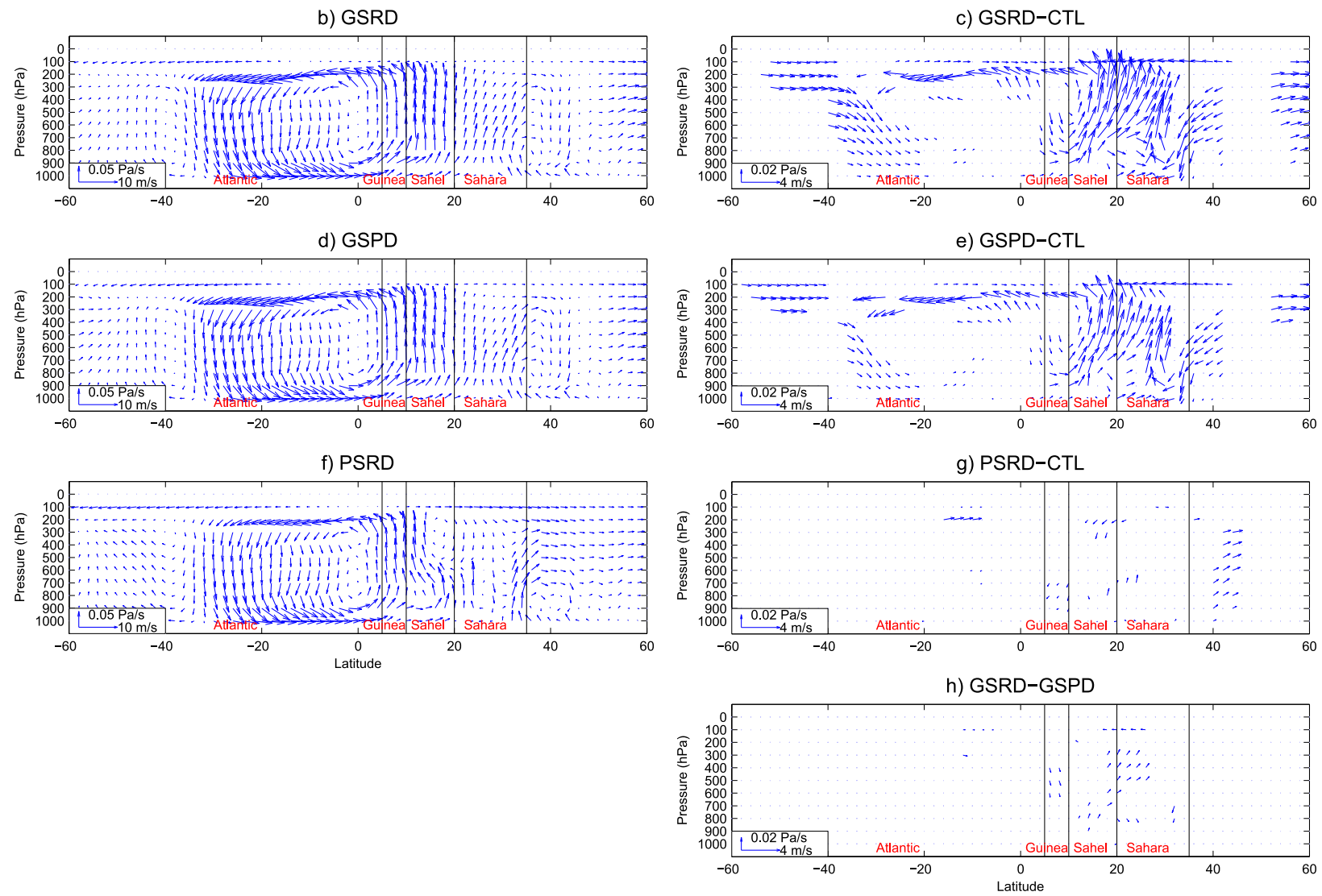

FIG. 6. JJAS meridional overturning circulation, represented through the meridional wind $\left(\mathrm{m} \mathrm{s}^{-1}\right)$ and the vertical velocity $\left(\mathrm{Pa} \mathrm{s}^{-1}\right)$, averaged in the range $\left[10^{\circ} \mathrm{W}-10^{\circ} \mathrm{E}\right]$ : (a),(b),(d),(f) climatological means for the CTL simulation and the sensitivity experiments, and (c), (e),(g) differences between the sensitivity experiments and the CTL simulation. (h) The difference between the GSRD and GSPD experiments. Significance at $95 \%$ confidence level is displayed.

of dust reduction in amplifying the anomalies when associated with land cover changes.

The changes in the WAM atmospheric dynamics are accompanied by important changes in the mechanisms driving the precipitation. A major source of synopticscale rainfall variability throughout present-day West Africa is associated with the African easterly waves (AEWs): westward-propagating disturbances with wavelengths of approximately $3000 \mathrm{~km}$ and periods below 5-6 days (Diedhiou et al. 1998). A longer-period regime of 6-9-day waves has also been identified in the region (Diedhiou et al. 1998, 1999), but these typically display a weaker association with precipitation $(\mathrm{Gu}$ et al. 2004). The AEWs are particularly important over

\section{(1)}


$\left[15^{\circ} \mathrm{N}, 0^{\circ} \mathrm{E}\right]$ is selected, similarly to studies analyzing the present-day monsoon (e.g., Diedhiou et al. 1999). For the GSPD and GSRD simulations, the location $\left[20^{\circ} \mathrm{N}, 0^{\circ} \mathrm{E}\right]$ is selected, reflecting the significant northward shift of the monsoonal circulation. It is noted that the results are relatively insensitive to small meridional shifts in the reference point (not shown; see also Gu et al. 2004). The precipitation is then averaged over the selected days and the JJAS climatology for each experiment is subtracted, in order to calculate the precipitation anomalies associated with wavy days in mm day ${ }^{-1}$. As a caveat, it is noted that this methodology implicitly assumes that all the precipitation occurring during a wavy day can be ascribed to MCSs associated with AEWs.

The CTL simulation displays a band of wave activity that originates west of the Ethiopian highlands and maximizes over western Sahel, propagating across the tropical Atlantic Ocean (Fig. 7a). This is similar to what seen in reanalysis data, albeit with larger variance values (see Fig. 3 in Skinner and Diffenbaugh 2013). Both the GSRD and GSPD experiments (Figs. 7b-e) show a northward shift and a marked weakening of the meridional wind variance in the region affected by the AEW activity. The difference between GSRD and GSPD indicates that the dust reduction favors a further weakening of the AEW activity in the presence of a vegetated Sahara (Fig. 7h). Similarly, the PSRD experiment presents a weakened AEW pattern relative to the CTL simulation (Figs. 7e,f).

Since the definition of a wavy day focuses on meridional wind maxima, their frequency is similar across all simulations, ranging from $25.5 \%$ in the CTL simulation to $24.0 \%$ in the PSRD case. However, the intensity of these AEW episodes shows a broader spread, with the CTL simulation displaying a mean filtered meridional wind velocity of $2.6 \mathrm{~m} \mathrm{~s}^{-1}$ compared to $2.3 \mathrm{~m} \mathrm{~s}^{-1}$ of the GSPD case and $2.1 \mathrm{~m} \mathrm{~s}^{-1}$ of the GSRD case. A one-sided two-sampled Kolmogorov-Smirnov test confirms that the cumulative distribution function of the AEW intensity for the GSPD case is larger than that of the CTL at the 95\% confidence level, indicating a shift of the distribution toward lower values.

The significant differences in the filtered meridional wind variance and AEW intensity result in equally large changes in the precipitation associated with the AEWs. The precipitation on wavy days is characterized by a multipolar anomaly pattern, clearly showing the signature of a propagating wave (Fig. 8). The peak precipitation anomalies driven by the AEW-associated MCSs are not collocated with the reference points at which the waves are identified. Rather, the peaks tend to occur to the west or southwest of the reference points, in close agreement with previous studies (e.g., Diedhiou et al. 1999; $\mathrm{Gu}$ et al. 2004). The peak average precipitation anomaly in the CTL simulation is $4.7 \mathrm{~mm}$ day $^{-1}$
(Fig. 8a), and wavy days account for $41.5 \%$ of the total seasonal precipitation at that location (Fig. 8b). The GSPD and GSRD simulations display a clear northward shift of the dipole, with a sizable reduction of the average peak precipitation anomalies on wavy days to 1.6 and $2.3 \mathrm{~mm} \mathrm{day}^{-1}$, respectively (Figs. 8c,e). These correspond to $36.5 \%$ and $33.3 \%$ of the total precipitation (Figs. 8d,f), respectively. The dust reduction alone leads to slight changes in this pattern, with a $4.1 \mathrm{~mm} \mathrm{day}^{-1}$ peak anomaly, representing $39.2 \%$ of the total precipitation.

The decreased importance of AEWs under Green Sahara conditions indicates a shift toward variability on time scales longer than the synoptic one. This is confirmed by a spectral analysis of precipitation and meridional wind at $700 \mathrm{hPa}$ over $\left[5^{\circ}-16^{\circ} \mathrm{N}, 10^{\circ} \mathrm{W}-10^{\circ} \mathrm{E}\right]$ for the CTL and PSRD simulations and $\left[5^{\circ}-28^{\circ} \mathrm{N}, 10^{\circ} \mathrm{W}-\right.$ $\left.10^{\circ} \mathrm{E}\right]$ for the GSRD and GSPD simulations. The different domains, as for the wavy day calculation, reflect the northward shift of the monsoon under a Green Sahara. The northern limits are chosen to roughly match the monsoon's northernmost extent, calculated following the methodology of Pausata et al. (2016). The CTL and PSRD meridional wind spectra display a clear peak around the AEW periodicity (2-5 days), while in the two Green Sahara scenarios the power in this band is weaker, and the spectra increase almost monotonically with period (Fig. 9b). The precipitation spectra (Fig. 9a) reflect this difference. In the CTL and PSRD simulations there is again a clear peak matching the AEW periodicity and highlighting the waves' dominant role in driving precipitation. In the two Green Sahara scenarios, the spectra show a roughly monotonic increase with period, suggesting that the 2-5-day band only accounts for a modest fraction of the total precipitation. Furthermore, while longer waves in the 6-9-day band grow in importance under a green Sahara, they do not play the same role as the 2-5-day band in the desert Sahara scenarios (Fig. 9). The Green Sahara simulations display a higher spectral power than the desert Sahara in both meridional wind and precipitation beyond $\sim 6$ days, but there is no clear peak to suggest that a specific dynamical mechanism is acting to enhance the precipitation over this frequency range.

Summarizing, the Green Sahara scenario is characterized by a widespread increase in precipitation, accompanied by a significant reduction in the 3-5-day AEW activity and in its ability to drive precipitation. The precipitation and meridional wind spectra show a shift toward longer periods and do not display any prominent peaks. This is somewhat surprising, because a sizable fraction of the present-day monsoonal precipitation is ascribed to the convection triggered by AEWs (Skinner and Diffenbaugh 2013). Hence, a more active AEW regime might be 


\section{JJAS AEWs : variance of $700 \mathrm{hPa}$ meridional wind (2.5-5-day filtered) $\left[\mathrm{m}^{2} / \mathrm{s}^{2}\right]$}

a) CTL

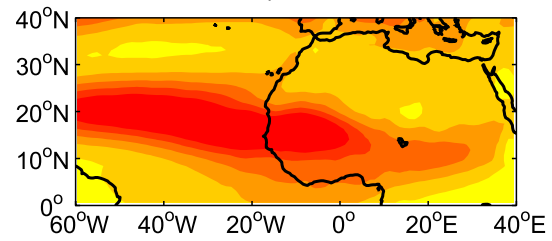

b) GSRD

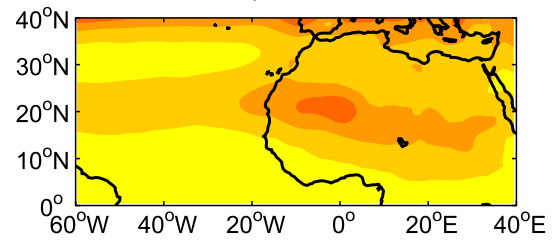

d) GSPD

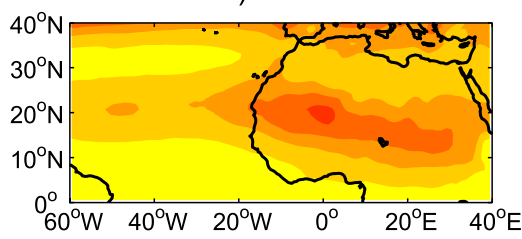

f) PSRD

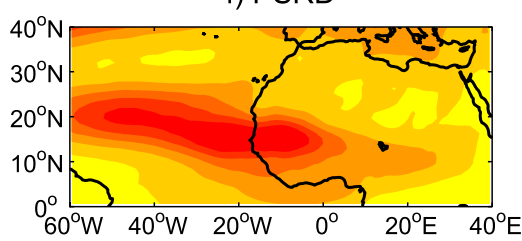

c) GSRD-CTL

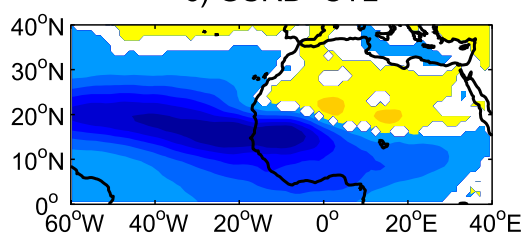

e) GSPD-CTL

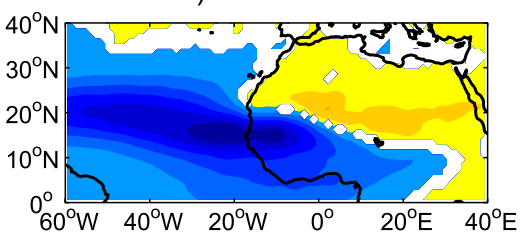

g) PSRD-CTL

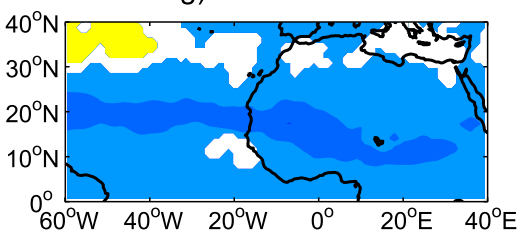

h) GSRD-GSPD

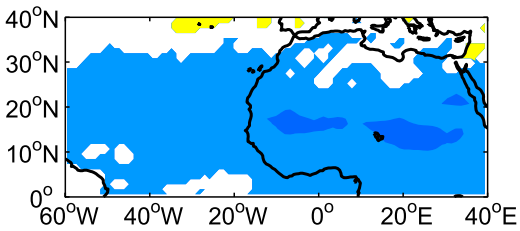

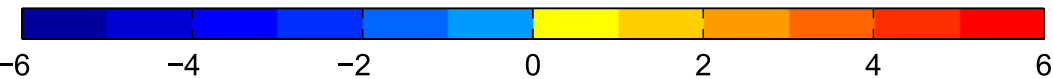

FIG. 7. JJAS African easterly wave activity, represented through the variance of the meridional wind at $700 \mathrm{hPa}$ filtered in the 2.5-5-day band $\left(\mathrm{m}^{2} \mathrm{~s}^{-2}\right)$ : (a),(b),(d),(f) climatological means for the CTL simulation and the sensitivity experiments, and (c),(e),(g) differences between the sensitivity experiments and the CTL simulation. (h) The difference between the GSRD and GSPD experiments. Significance at $95 \%$ confidence level is displayed, computed by using a two-sample $\mathrm{F}$ test.

expected under an intensified $\mathrm{MH}$ monsoon, due to the increased latent heat and convection associated with the increased precipitation. This apparent contradiction can be reconciled by considering the role of the AEJ in triggering and strengthening the AEWs, through barotropic-baroclinic instabilities (Thorncroft and Hoskins 1994). Wu et al. (2012) found that synoptic disturbances are more likely where the zonal flow is stronger and that the more unstable waves are likely to be closer to the zonal flow maximum (i.e., closer to an intense AEJ core). It is 
a) CTL JJAS AEW-precip [mm/day] ( $\max =4.7 \mathrm{~mm} /$ day)

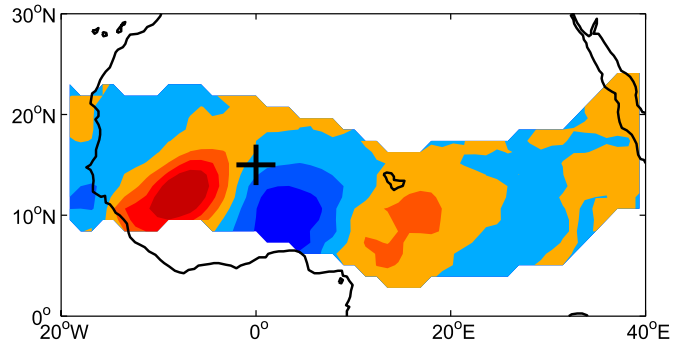

c) GSRD ( $\max =2.3 \mathrm{~mm} /$ day)

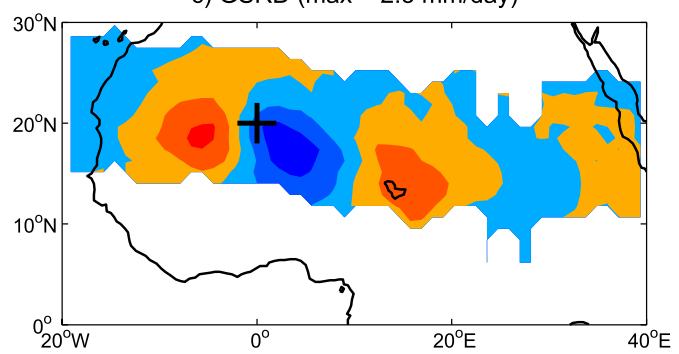

e) GSPD ( $\max =1.6 \mathrm{~mm} /$ day $)$

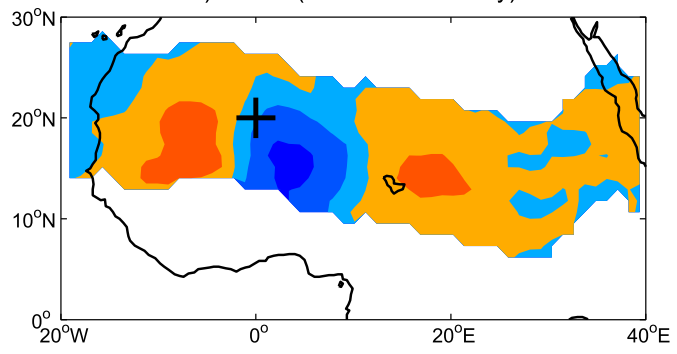

g) PSRD ( $\max =4.1 \mathrm{~mm} /$ day $)$
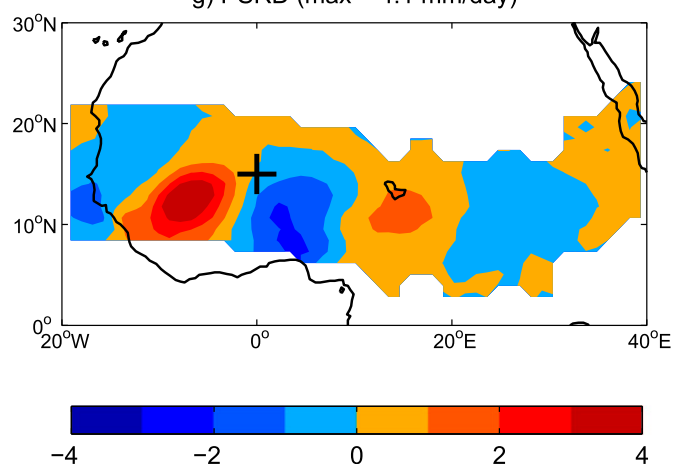

b) CTL JJAS AEW-precip fraction [\%] ( $\max =42 \%)$

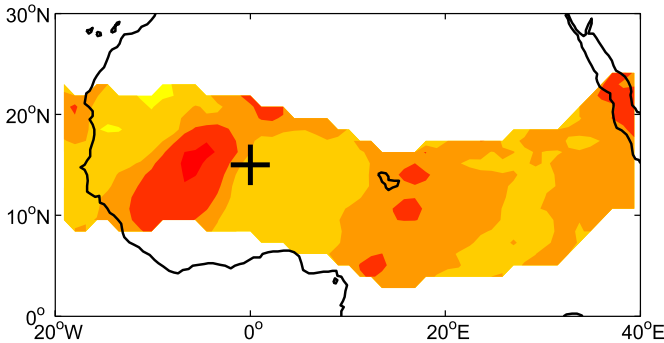

d) GSRD $(\max =33 \%)$

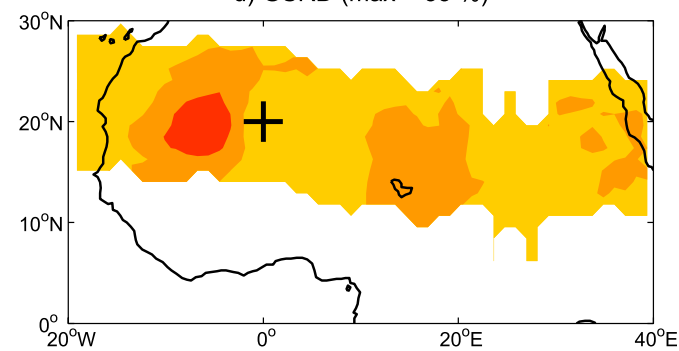

f) GSPD (max $=37 \%)$

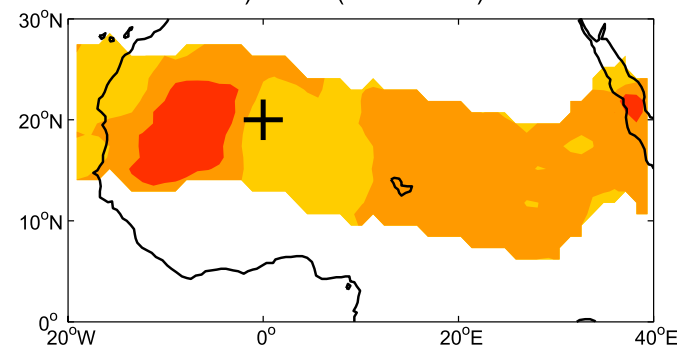

h) PSRD $(\max =39 \%)$

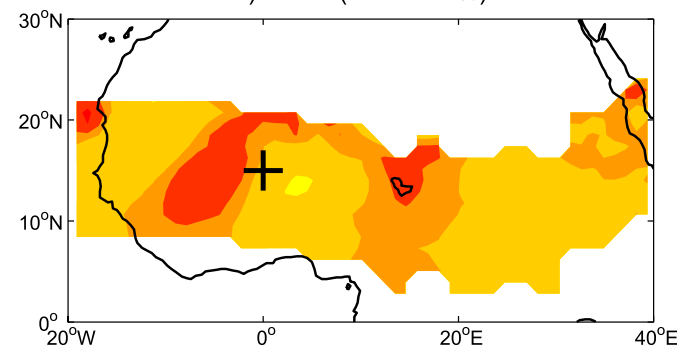

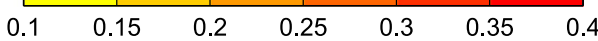

FIG. 8. Precipitation associated with the African easterly waves detected in JJAS at locations indicated by black crosses: (a),(c),(e),(g) precipitation anomalies $\left(\mathrm{mm} \mathrm{day}^{-1}\right)$ compared to the JJAS climatology, and (b),(d),(f),(h) fraction of the JJAS total precipitation. In brackets at the top of each panel, values and fraction of the peak precipitation anomaly to the west of the black crosses. Only values in a $15^{\circ}$ latitudinal band around the maximum of the meridional wind variance (see Fig. 7) are displayed.

therefore argued that, in the Green Sahara scenarios, the radical modification of the AEJ dynamics dominates the thermodynamic changes; the sizable northward migration $\left(+6.5^{\circ}\right)$ and weakening $\left(-2.7 \mathrm{~m} \mathrm{~s}^{-1}\right)$ are more effective in shifting and suppressing the wave activity than the latent heat and convection increase in enhancing it. Finally, it is highlighted that the dust reduction induces opposite responses in the atmospheric dynamics, depending on the land cover of the Sahara: it leads to more or less favorable conditions for 
a) Precipitation

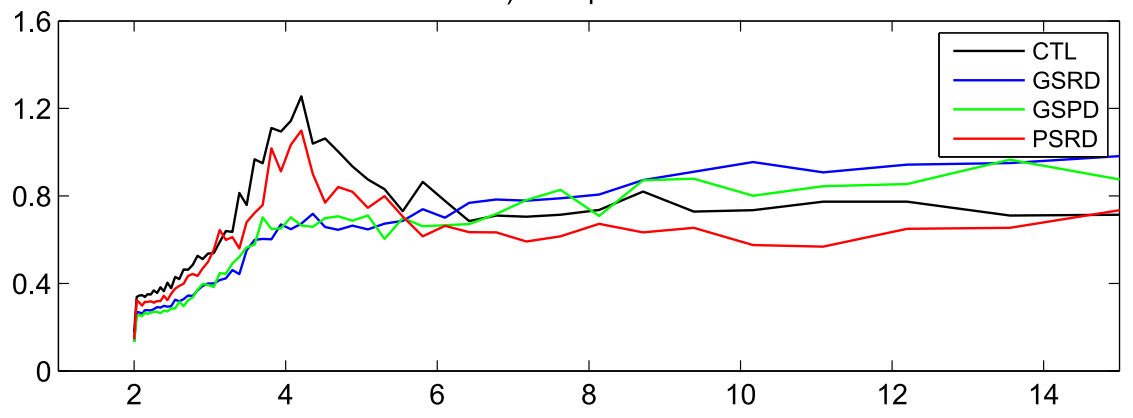

b) Meridional wind at $700 \mathrm{hPa}$

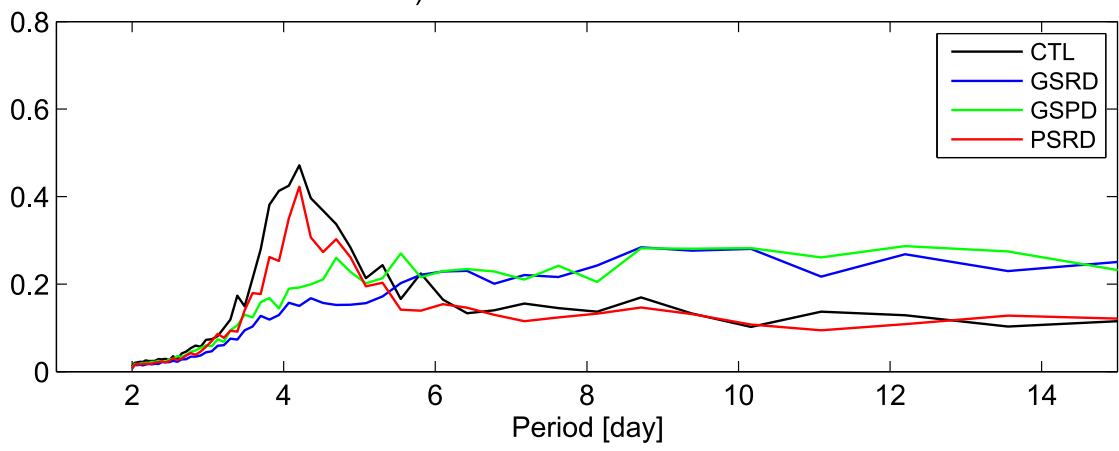

FIG. 9. Fast Fourier transform analysis of gridpoint JJAS daily (a) precipitation and (b) meridional wind at $700 \mathrm{hPa}$, averaged over $5^{\circ}-16^{\circ} \mathrm{N}, 10^{\circ} \mathrm{W}-10^{\circ} \mathrm{E}$ for the CTL and PSRD simulations and $5^{\circ}-28^{\circ} \mathrm{N}, 10^{\circ} \mathrm{W}-10^{\circ} \mathrm{E}$ for the GSRD and GSPD simulations.

precipitation when associated with a vegetated or desert surface, respectively.

\section{b. Energy budget}

The rainfall and atmospheric circulation patterns simulated in the sensitivity experiments are closely linked to the changes in surface conditions and radiative properties of the atmosphere, which in turn affect the energetics and dynamics of the WAM. This section elucidates the links between energetics, precipitation, and dynamics in the sensitivity experiments, through the analysis of the atmospheric radiative and heat fluxes, and moist static energy (MSE) content.

The greening of the Sahara (GSPD simulation) lowers the surface albedo over a vast portion of North Africa (see Table 1), leading to an increase in the net flux of the clearsky downward SW radiation at the top of the atmosphere (TOA) (Fig. 10c). The downward SW flux anomaly is almost uniform and limited to the area where the surface albedo is lowered. The reduction in dust concentration when the Sahara is deserted (PSRD simulation) leads to an upward SW flux anomaly at the TOA, in which the fingerprint of the dust reduction pattern is evident (Fig. 10e). The upward SW flux is due to the increase in the planetary albedo produced by the removal of airborne dust over a bright surface. On the contrary, the removal of airborne dust when the Sahara is vegetated (GSRD simulation) further reduces the planetary albedo of a dark surface, enhancing the downward flux anomaly of SW radiation simulated in the GSPD experiment (Fig. 10a), although the effect is quite weak (Fig. 10g).

At the surface, the effect of greening the Sahara (GSPD simulation) is similar to the TOA, resulting in a positive anomaly of the downward SW radiation, limited to the area where the surface albedo is reduced (Fig. 10d). A widespread increase in the downward SW radiation at the surface is also simulated in the PSRD experiment (Fig. 10f), in which the removal of airborne dust reduces the absorption of the solar radiation, especially at latitudes around $15^{\circ} \mathrm{N}$, where dust concentration is maximum (see Fig. 1). By reducing the absorption of solar radiation, the removal of airborne dust over the Green Sahara (GSRD simulation) enhances the positive anomaly in the downward SW radiation due to the lower surface albedo (Figs. 10b,h).

In the Green Sahara experiments, the SW radiative forcing simulated at the surface over the Sahel and Sahara is accompanied by a negative (i.e., upward) anomaly in the sensible heat $(\mathrm{SH})$ flux, which reverts to positive (i.e., downward) between $10^{\circ}$ and $20^{\circ} \mathrm{N}$ due to the cooling effect of the precipitation anomalies (Figs. 11a,c; cf. 
TOA SW net flux $\left[\mathrm{W} / \mathrm{m}^{2}\right]$

a) GSRD-CTL

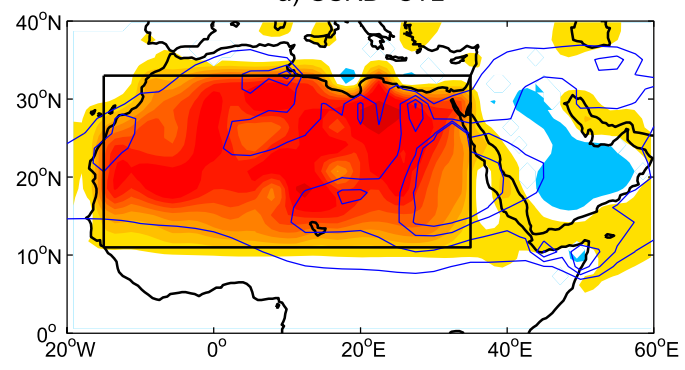

c) GSPD-CTL

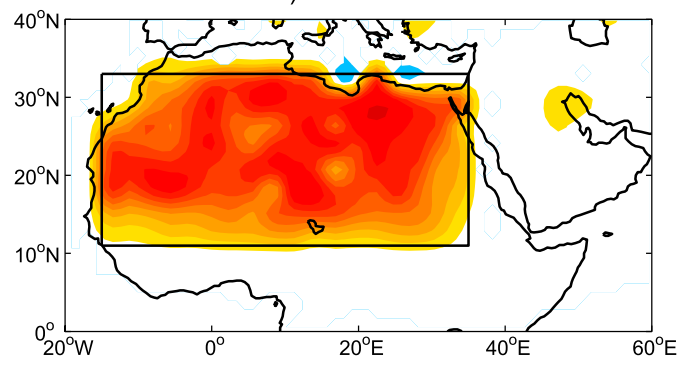

e) PSRD-CTL

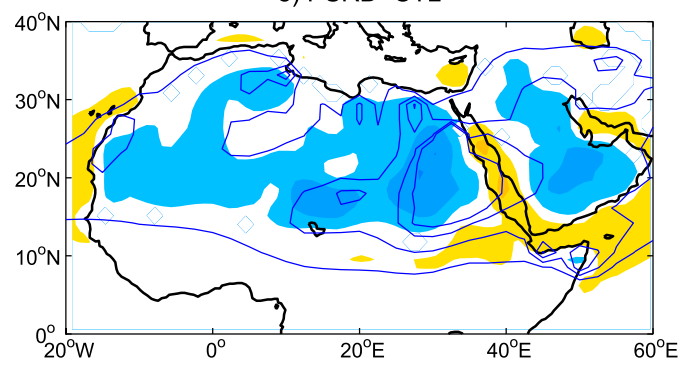

g) GSRD-GSPD

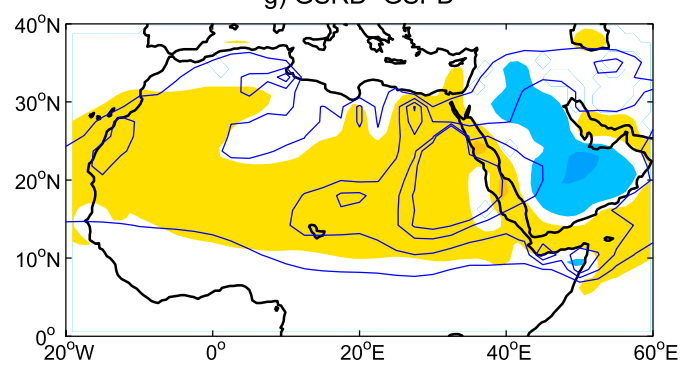

$-100-80-60-40-20-55 \quad 20 \quad 40 \quad 60 \quad 80 \quad 100$
Surface SW net flux $\left[\mathrm{W} / \mathrm{m}^{2}\right]$

b) GSRD-CTL

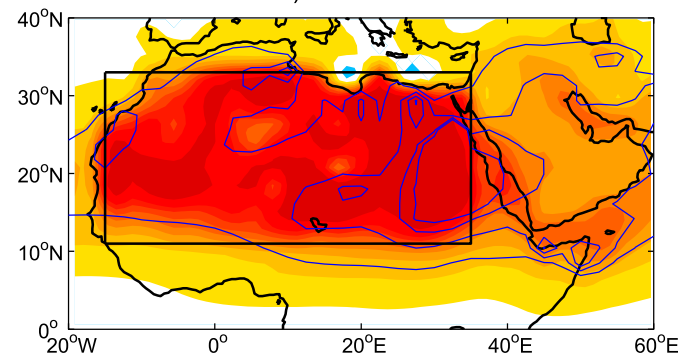

d) GSPD-CTL

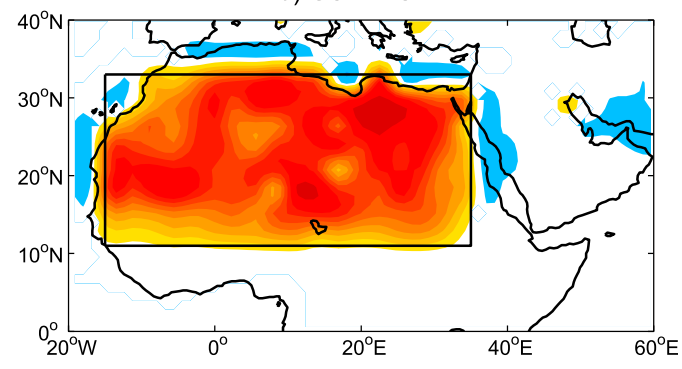

f) PSRD-CTL

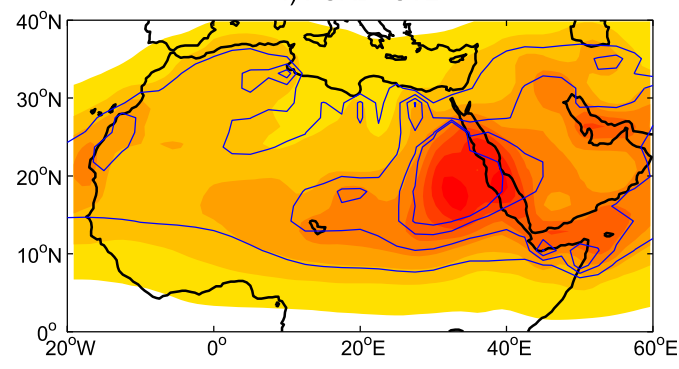

h) GSRD-GSPD

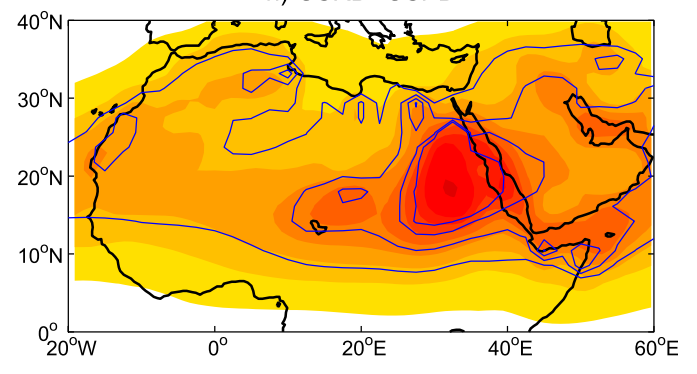

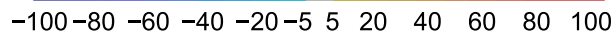

FIG. 10. JJAS clear-sky SW radiation net flux $\left(\mathrm{W} \mathrm{m}^{-2}\right)$ at (a),(c),(e),(g) TOA and (b),(d),(f),(h) surface: (a)-(f) differences between the sensitivity experiments and the CTL simulation and (g),(h) the GSRD - GSPD difference. Significance at $95 \%$ confidence level is displayed. Radiation is represented as $24-\mathrm{h}$ means; positive values indicate downward net flux. The black rectangle represents the domain where the change in land cover is applied in the Green Sahara experiments. Blue contours display the dust column concentration anomaly in the reduced dust experiments (contours at $-2,-1.5,-1$, and $-0.5 \mathrm{mg} \mathrm{kg}^{-1}$; see Fig. 1b). 
Surface SH flux $\left[\mathrm{W} / \mathrm{m}^{2}\right]$

a) GSRD-CTL

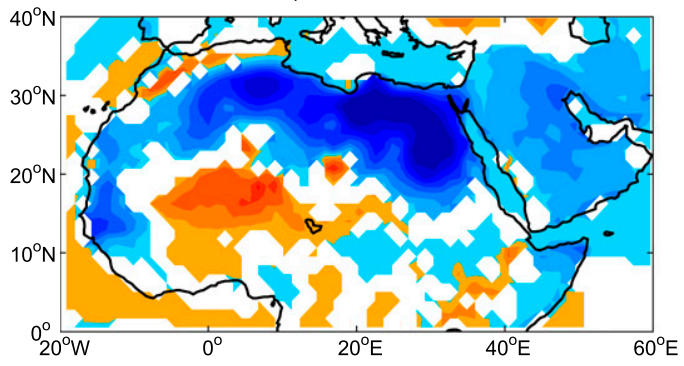

c) GSPD-CTL

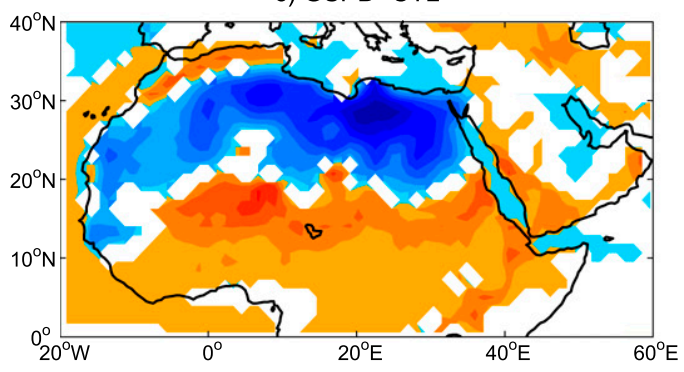

e) PSRD-CTL

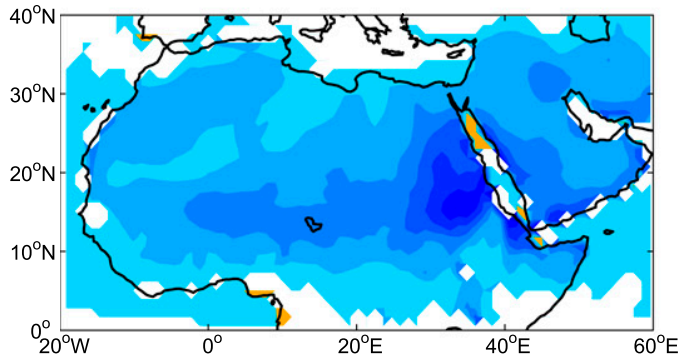

g) GSRD-GSPD
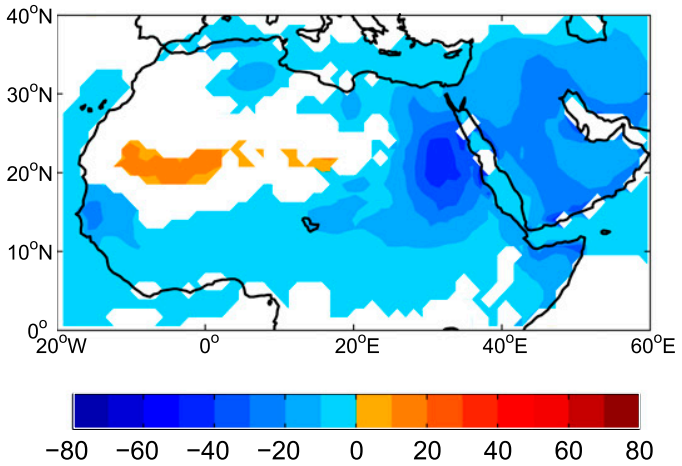

Surface LH flux $\left[\mathrm{W} / \mathrm{m}^{2}\right]$

b) GSRD-CTL

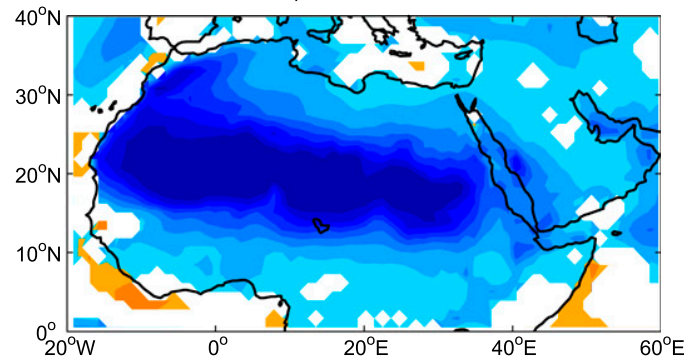

d) GSPD-CTL

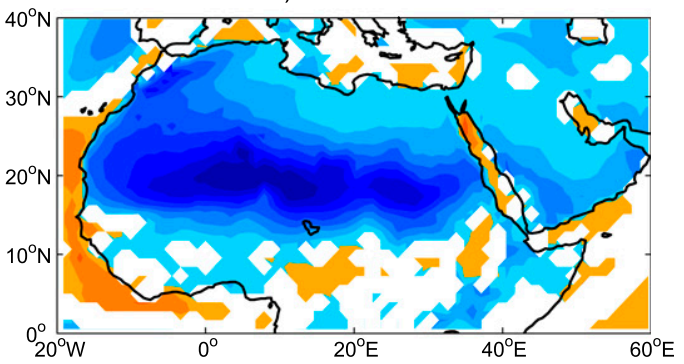

f) PSRD-CTL

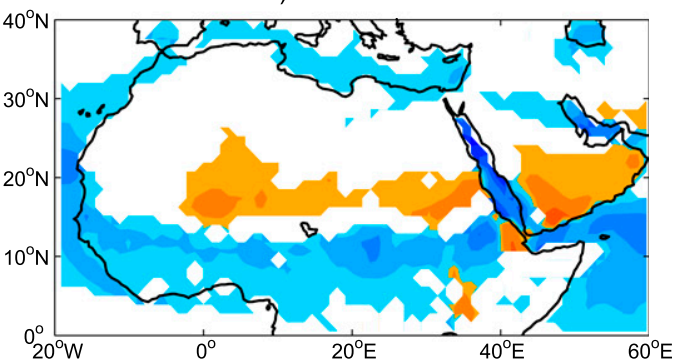

h) GSRD-GSPD

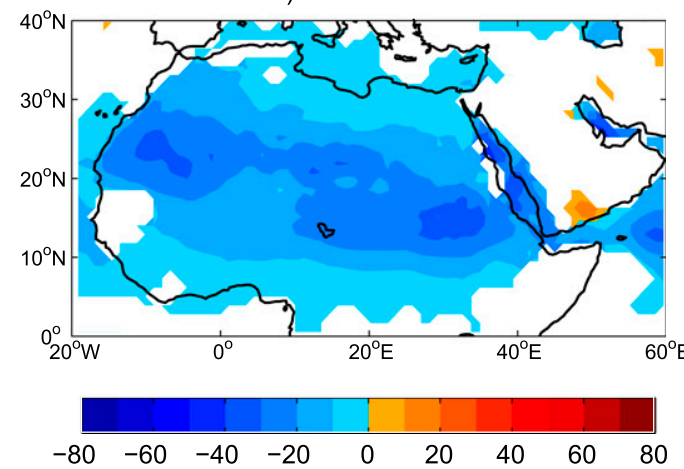

FIG. 11. JJAS surface (a),(c),(e),(g) sensible and (b),(d),(f),(h) latent heat flux (W m $\left.{ }^{-2}\right)$ : (a)-(f) differences between the sensitivity experiments and the CTL simulation and (g),(h) GSRD - GSPD difference. Significance at $95 \%$ confidence level is displayed. Positive values indicate downward flux.

Fig. 2). The additional SW radiative forcing in the GSRD simulation, associated with the dust reduction, limits the upward SH flux in the eastern Sahel (Figs. 11a,g). In the PSRD simulation, the upward SH flux anomaly is widespread, peaking between $10^{\circ}$ and $20^{\circ} \mathrm{N}$, where the SW radiative forcing is maximum (Fig. 11e; cf. Fig. 10f). The latent heat (LH) flux at the surface shows significant negative (i.e., upward) 
anomalies in the Green Sahara scenarios (Figs. 11b,d). The release of LH into the atmosphere is associated with enhanced evaporation over the vegetated surface, induced by the SW radiative forcing. The $\mathrm{LH}$ response is shaped by the precipitation anomalies, further enhancing evaporation (Figs. 11b,d; cf. Fig. 2). The reduction in dust concentration over the Green Sahara increases SW radiative forcing and precipitation at the surface, strengthening the LH release into the atmosphere (Fig. 11h). Reduction in dust concentration alone (PSRD simulation) results in LH release over the vegetated Sahel (south of $15^{\circ} \mathrm{N}$ ), induced by the SW radiative forcing, while the decreased precipitation leads to negative anomalies in the LH flux north of $15^{\circ} \mathrm{N}$ (Fig. 11f).

The combination of the $\mathrm{LH}$ and $\mathrm{SH}$ fluxes results in an intense upward heat flux over the Sahara in the Green Sahara experiments, and a weaker upward flux peaking over the Sahel in the PSRD experiment (Fig. S6). The heat flux then triggers moist convection, whose modifications are diagnosed in the sensitivity experiments through the MSE content of the atmosphere. This is defined as the sum of geopotential, enthalpy, and latent heat:

$$
\mathrm{MSE}=g z+C_{p} T+L q,
$$

where $g$ is the gravitational acceleration, $z$ the geopotential height, $C_{p}$ the specific heat of dry air at constant pressure, $T$ temperature, $L$ the latent heat of evaporation, and $q$ the specific humidity. The MSE is a direct indicator of the monsoonal precipitation, because the transformation of enthalpy and latent energy available in the lower troposphere into geopotential energy aloft is the main signal of convection (Fontaine and Philippon 2000). In the GSRD simulation, the meridional profile of the MSE atmospheric content shows an intense positive anomaly dominating the entire troposphere from $15^{\circ}$ to $35^{\circ} \mathrm{N}$ (Fig. 12a). Close to the surface, at $1000 \mathrm{hPa}$, the MSE peak moves $6^{\circ}$ northward (from $14^{\circ} \mathrm{N}$ in CTL to $20^{\circ} \mathrm{N}$; Fig. S7), accompanied by an increase in the meridional difference between the peak and the Guinea Coast $\left(+1.7 \mathrm{~kJ} \mathrm{~kg}^{-1}\right.$; Fig. S7). The GSPD simulation shows a similar pattern, characterized by weaker anomalies (Figs. 12b,d): a $+5^{\circ}$ migration of the MSE peak and a $1.2 \mathrm{~kJ} \mathrm{~kg}^{-1}$ increase in the meridional difference with the Guinea Coast (Fig. S7). These modifications elucidate the precipitation response in the Green Sahara experiments: the meridional migration and intensification of the peak MSE favor the northward penetration of the precipitation belt, and the MSE excess in the lower and middle troposphere triggers deep convection over the Sahara. In the PSRD simulation (Fig. 12c), the MSE content shows a negative anomaly in the middle-upper troposphere, and a weakening of the maximum close to
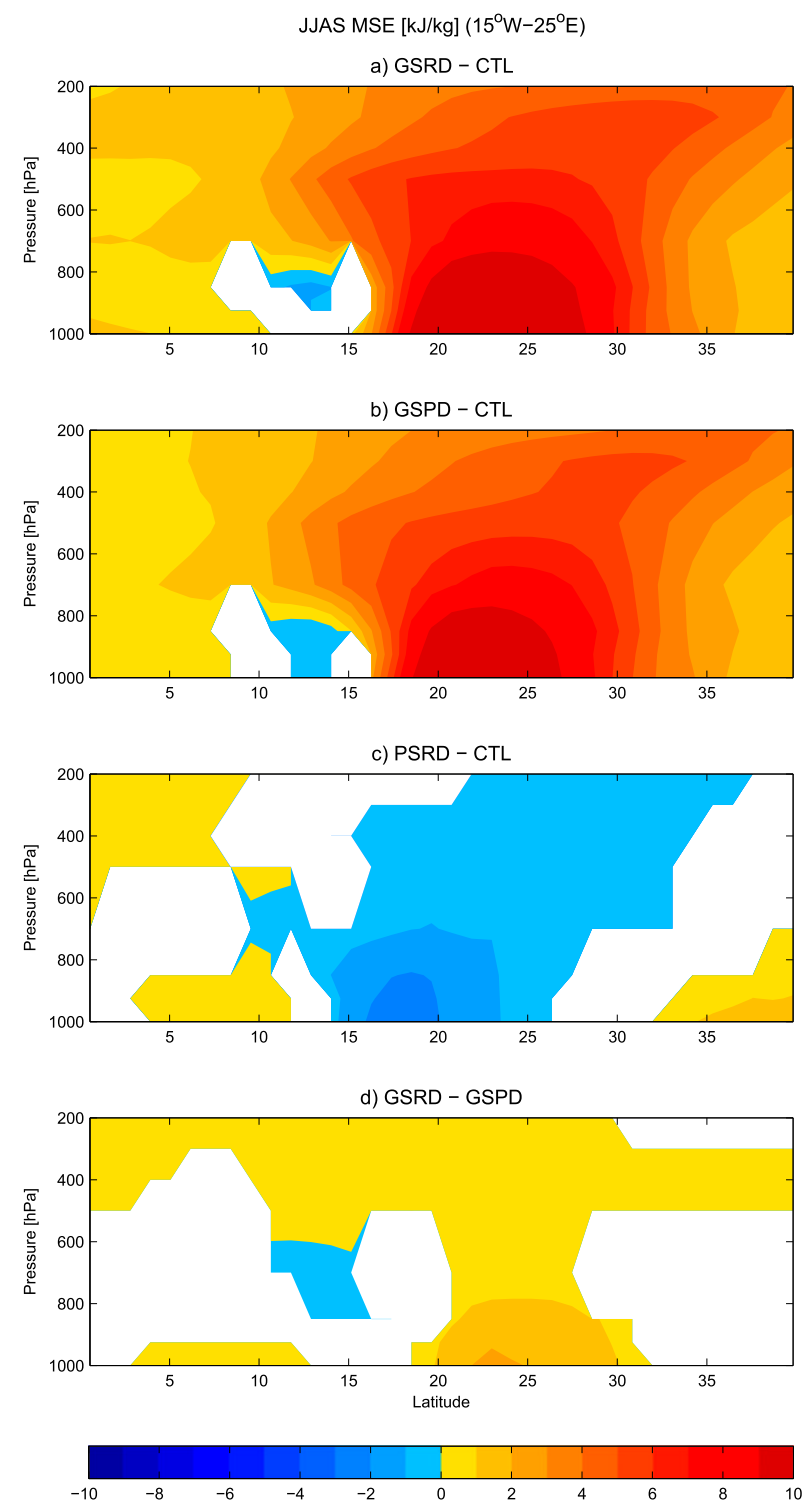

FIG. 12. JJAS moist static energy $\left(\mathrm{kJ} \mathrm{kg}^{-1}\right)$, averaged between $15^{\circ} \mathrm{W}$ and $25^{\circ} \mathrm{E}$ : (a)-(c) differences between the sensitivity experiments and the CTL simulation and (d) the GSRD - GSPD difference. Significance at $95 \%$ confidence level is displayed.

the surface $\left(-0.7 \mathrm{~kJ} \mathrm{~kg}^{-1}\right.$ at $1000 \mathrm{hPa}$; Fig. S7), resulting in a weaker monsoonal circulation.

\section{Discussion and conclusions}

The objective of this study is to improve the understanding of the changes in the West African monsoon dynamics and precipitation patterns during the mid-Holocene, when a large part of North Africa was characterized by a mesic environment and the Sahara was extensively covered by vegetation. A set of idealized 
sensitivity experiments, performed with the EC-Earth climate model, has been used to understand the changes in atmospheric circulation that characterized that period. In these simulations, vegetation cover over the Sahara and a reduction in atmospheric mineral dust concentrations are imposed together and in turn.

By using this set of simulations, Pausata et al. (2016) showed that the vegetation cover over the Sahara is the primary driver of a radical alteration of the West African monsoon during the mid-Holocene, with the associated dust reduction further strengthening precipitation anomalies inland. The precipitation simulated in their "Green Sahara and reduced dust" experiment is indeed quantitatively consistent with estimations of the mid-Holocene precipitation based on paleoclimate proxy data (Tierney et al. 2017). This study further extends the analysis performed by Pausata et al. (2016) to improve the understanding of the changes in the monsoonal dynamics accompanying the precipitation anomalies. The modifications of the radiative balance at the surface and the TOA are also discussed, along with the consequent response of the energetics of the monsoonal system.

When a vegetation cover is prescribed over the Sahara (experiment GSPD), a dramatic response in the West African monsoon is simulated. The lowering of the surface albedo induces an intense positive radiative forcing at the TOA and at the surface over the Sahara, leading to a release of sensible and latent heat into the atmosphere. The heat flux anomaly triggers moist convection over this region, driving a northward expansion of the monsoonal precipitation belt, which extends up to the Mediterranean coast. A substantial modification of the regional circulation is also simulated, with critical alterations in some of the "classical" dynamical features of the West African monsoon, such as the Saharan heat low, the African easterly jet, and the African easterly wave regime. In particular, a weakening of the African easterly wave activity is associated with a decrease in wave-related precipitation, suggesting a reduction of the African easterly waves' role in triggering and organizing mesoscale convective systems. These changes follow a general reorganization of the circulation toward a cyclonic gyre throughout the troposphere. This analysis suggests that a vegetated Sahara may radically change the regional circulation pattern over West Africa.

On the opposite, dust reduction alone (experiment PSRD) leads to a slight weakening in the monsoonal circulation and precipitation rates. This weakening is associated with a positive surface radiative forcing in the Sahel and a radiative cooling in the middle and upper troposphere over the Sahara, resulting in a reduction of the meridional energy gradient over West Africa, which prevents monsoonal precipitation from penetrating inland.
The effect of dust removal on the radiative balance of the atmosphere depends on the radiative properties of the airborne dust in association with the underlying land cover. Indeed, in PI conditions dust reduction increases the planetary albedo above the Sahara Desert, cooling the middle and upper troposphere, and induces a positive radiative forcing at the surface, peaking in the vegetated Sahel. On the contrary, when a vegetated surface is prescribed from the Sahel to the Sahara, dust reduction lowers the planetary albedo, warming the middle to upper troposphere, and induces a positive radiative forcing at the surface, peaking in the SahelSahara transition zone where PI dust concentration is maximum.

The radical modification of the atmospheric circulation over North Africa discussed in this study is likely to have trigged a chain of global-scale changes during the mid-Holocene. For example, Muschitiello et al. (2015), using the same model as in this study, show that the desertification of the Sahara at the end of the African Humid Period led to a reduction in the atmospheric and oceanic poleward heat transport from tropical to high northern latitudes. The reduction in the poleward heat transport weakened the midlatitude westerlies, resulting in more negative Arctic Oscillation-like conditions and a consequent cooling over the Arctic and North Atlantic regions. Results presented in this paper show that the greening of the Sahara triggers a strong reduction in the African easterly wave activity, which is known to be related with the formation of tropical cyclones in the Atlantic Ocean (Price et al. 2015). Therefore, the decreased wave activity may induce a reduction in tropical storms developing in the North Atlantic. On the other hand, the reduction in the Saharan dust emission and transport across the tropical Atlantic is favorable to the development of tropical cyclones in the basin, through the radiative warming of the ocean surface (Evan et al. 2006), indicating possible competing effects of the vegetation and dust changes in the Sahara on the Atlantic hurricane season. Furthermore, reducing African easterly waves may initially lead to fewer tropical cyclones but, because of that, the ocean would warm, compensating for the reduced wave activity (assuming no other changes in the thermodynamic structure of the atmosphere). Therefore, the combination of Sahara greening and reduced dust emission during the mid-Holocene may have led to an increased number of tropical cyclones in the Atlantic. By analyzing the same set of simulations used in this study, Pausata et al. (2017a) show indeed an increase in the tropical cyclone activity in both the hemispheres and particularly over the Caribbean basin and the east coast of North America. This hypothesis cannot be tested with current paleotempestology archives 
that are geographically and temporally patchy, and hence unable to provide a complete view of the Holocene storm activity. However, a proxy-data reconstruction from Puerto Rico suggests a positive correlation between West African monsoon strength and tropical cyclone intensity over the last 5500 years (Donnelly and Woodruff 2007). In particular, the period between 2500 and 1000 years BP was the most active tropical storm interval in Puerto Rico and was characterized by a stronger WAM and a reduced Saharan dust flux relative to the following millennium (Mulitza et al. 2010). In addition, Williams et al. (2016) emphasized the relationship between reduced dust loading during the early and mid-Holocene and the northward expansion of the ITCZ, which in turn can intensify tropical storm activity in the western North Atlantic (van Hengstum et al. 2016). Pausata et al. (2017b) also show reduced El Niño-Southern Oscillation (ENSO) variability and La Niña-like conditions in winter in a Green Sahara scenario, compared to preindustrial and standard CMIP/PMIP mid-Holocene scenarios. These changes in ENSO mean state and variability are in general favorable to tropical storm activity in the North Atlantic basin (Chiacchio et al. 2017). Further efforts both from the modeling and the proxy community are necessary to better understand the remote teleconnections associated to the West African monsoon variability.

The findings of this study are also useful in a future perspective, at regional and global scales. Indeed, the possible positive trend in Sahelian precipitation projected for the twenty-first century (Biasutti 2013) may be accompanied and amplified by land cover and dust reduction feedbacks, which in turn may impact climate in remote regions.

Acknowledgments. M.G. has been supported by the LABEX project, funded by Agence Nationale de la Recherche (French National Research Agency, Grant ANR-10-LABX-18-01). G.M. has been supported by the MILEX project, funded by the Swedish Research Council (Vetenskapsrådet Grant 2012-40395-98427-17) and a grant from the Department of Meteorology of Stockholm University. Q.Z. acknowledges funding from Swedish Research Council VR for the Swedish-French project "Greenland in a warming Arctic." F.S.R.P. acknowledges funding from the Swedish Research Council (FORMAS) as part of the Joint Programming Initiative on Climate and the Belmont Forum for the project "Palaeo-constraints on Monsoon Evolution and Dynamics (PACMEDY)" (Grant FR-2016/0001). The simulations with EC-Earth were performed on supercomputer provided by the Swedish National Infrastructure for Computing (SNIC) at NSC and Cray XC30 HPC systems at ECMWF. The authors thank three anonymous reviewers for their constructive comments, which led to a substantial improvement of the manuscript.

\section{REFERENCES}

Albani, S., and Coauthors, 2014: Improved dust representation in the Community Atmosphere Model. J. Adv. Model. Earth Syst., 6, 541-570, doi:10.1002/2013MS000279.

Biasutti, M., 2013: Forced Sahel rainfall trends in the CMIP5 archive. J. Geophys. Res. Atmos., 118, 1613-1623, doi:10.1002/ jgrd.50206.

_ A. H. Sobel, and S. J. Camargo, 2009: The role of the Sahara low in summertime Sahel rainfall variability and change in the CMIP3 models. J. Climate, 22, 5755-5771, doi:10.1175/ 2009JCLI2969.1.

Braconnot, P., S. P. Harrison, B. Otto-Bliesner, A. Abe-Ouchi, J. Jungclaus, and J. Y. Peterschmitt, 2011: The Paleoclimate Modeling Intercomparison Project contribution to CMIP5. CLIVAR Exchanges, Vol. 16, International CLIVAR Project Office, Southampton, United Kingdom, 15-19.

Chen, T.-C., 2005: Maintenance of the midtropospheric North African summer circulation: Saharan high and African easterly jet. J. Climate, 18, 2943-2962, doi:10.1175/JCLI3446.1.

Chiacchio, M., F. S. R. Pausata, G. Messori, A. Hannachi, M. Chin, T. Önskog, A. M. L. Ekman, and L. Barrie, 2017: On the links between meteorological variables, aerosols, and tropical cyclone frequency in individual ocean basins. J. Geophys. Res., 122, 802-822, doi:10.1002/2015JD024593.

Claussen, M., and V. Gayler, 1997: The greening of the Sahara during the mid-Holocene: Results of an interactive atmosphere-biome model. Global Ecol. Biogeogr. Lett., 6, 369-377, doi:10.2307/ 2997337.

deMenocal, P. B., J. Ortiz, T. Guilderson, J. Adkins, M. Sarnthein, L. Baker, and M. Yarusinsky, 2000: Abrupt onset and termination of the African Humid Period: Rapid climate responses to gradual insolation forcing. Quat. Sci. Rev., 19, 347-361, doi:10.1016/S0277-3791(99)00081-5.

Diedhiou, A., S. Janicot, A. Viltard, and P. de Felice, 1998: Evidence of two regimes of easterly waves over West Africa and the tropical Atlantic. Geophys. Res. Lett., 25, 2805-2808, doi:10.1029/98GL02152.

,,,--- , and H. Laurent, 1999: Easterly wave regimes and associated convection over West Africa and the tropical Atlantic: Results from the NCEP/NCAR and ECMWF reanalyses. Climate Dyn., 15, 795-822, doi:10.1007/ s003820050316.

Donnelly, J. P., and J. D. Woodruff, 2007: Intense hurricane activity over the past 5,000 years controlled by El Niño and the West African monsoon. Nature, 447, 465-468, doi:10.1038/ nature 05834 .

Egerer, S., M. Claussen, C. Reick, and T. Stanelle, 2016: The link between marine sediment records and changes in Holocene Saharan landscape: Simulating the dust cycle. Climate Past, $\mathbf{1 2}$, 1009-1027, doi:10.5194/cp-12-1009-2016.

Evan, A. T., J. Dunion, J. A. Foley, A. K. Heidinger, and C. S. Velden, 2006: New evidence for a relationship between Atlantic tropical cyclone activity and African dust outbreaks. Geophys. Res. Lett., 33, L19813, doi:10.1029/2006GL026408.

- C. Flamant, M. Gaetani, and F. Guichard, 2016: The past, present and future of African dust. Nature, 531, 493-495, doi:10.1038/nature17149.

Fontaine, B., and N. Philippon, 2000: Seasonal evolution of boundary layer heat content in the West African monsoon from the 
NCEP/NCAR. Int. J. Climatol., 20, 1777-1790, doi:10.1002 1097-0088(20001130)20:14<1777::AID-JOC568>3.0.CO;2-S.

Gaetani, M., C. Flamant, S. Bastin, S. Janicot, C. Lavaysse, F. Hourdin, P. Braconnot, and S. Bony, 2016: West African monsoon dynamics and precipitation: The competition between global SST warming and $\mathrm{CO}_{2}$ increase in CMIP5 idealized simulations. Climate Dyn., 48, 1353-1373, doi:10.1007/ s00382-016-3146-z.

Gasse, F., 2000: Hydrological changes in the African tropics since the Last Glacial Maximum. Quat. Sci. Rev., 19, 189-211, doi:10.1016/S0277-3791(99)00061-X.

Giannini, A., 2010: Mechanisms of climate change in the semiarid African Sahel: The local view. J. Climate, 23, 743-756, doi:10.1175/2009JCLI3123.1.

Ginoux, P., J. M. Prospero, T. E. Gill, N. C. Hsu, and M. Zhao, 2012: Global-scale attribution of anthropogenic and natural dust sources and their emission rates based on MODIS Deep Blue aerosol products. Rev. Geophys., 50, RG3005, doi:10.1029/ 2012RG000388.

Gu, G., R. F. Adler, G. J. Huffman, and S. Curtis, 2004: African easterly waves and their association with precipitation. J. Geophys. Res., 109, D04101, doi:10.1029/2003JD003967.

Harrison, S. P., and Coauthors, 2014: Climate model benchmarking with glacial and mid-Holocene climates. Climate Dyn., $\mathbf{4 3}$, 671-688, doi:10.1007/s00382-013-1922-6.

— , P. J. Bartlein, K. Izumi, G. Li, J. Annan, J. Hargreaves, P. Braconnot, and M. Kageyama, 2015: Evaluation of CMIP5 palaeo-simulations to improve climate projections. Nat. Climate Change, 5, 735-743, doi:10.1038/nclimate2649.

Hazeleger, W., and Coauthors, 2010: EC-Earth: A seamless Earthsystem prediction approach in action. Bull. Amer. Meteor. Soc., 91, 1357-1363, doi:10.1175/2010BAMS2877.1.

Hély, C., and Coauthors, 2014: Holocene changes in African vegetation: Tradeoff between climate and water availability. Climate Past, 10, 681-686, doi:10.5194/cp-10-681-2014.

Holmes, J. A., 2008: How the Sahara became dry. Science, 320, 752-753, doi:10.1126/science. 1158105.

IFAD, 2013: Rainfed food crops in West and Central Africa. A Savoir Series, Vol. 6, International Fund for Agricultural Development and Agence Française de Développement, 183 pp.

Kröpelin, S., and Coauthors, 2008: Climate-driven ecosystem succession in the Sahara: The past 6000 years. Science, 320, 765768, doi:10.1126/science.1154913.

Lavaysse, C., C. Flamant, S. Janicot, D. J. Parker, J. P. Lafore, B. Sultan, and J. Pelon, 2009: Seasonal evolution of the West African heat low: A climatological perspective. Climate Dyn., 33, 313-330, doi:10.1007/s00382-009-0553-4.

Levis, S., G. B. Bonan, and C. Bonfils, 2004: Soil feedback drives the mid-Holocene North African monsoon northward in fully coupled CCSM2 simulations with a dynamic vegetation model. Climate Dyn., 23, 791-802, doi:10.1007/ s00382-004-0477-y.

Lézine, A.-M., C. Hély, C. Grenier, P. Braconnot, and G. Krinner, 2011: Sahara and Sahel vulnerability to climate changes, lessons from Holocene hydrological data. Quat. Sci. Rev., 30, 3001-3012, doi:10.1016/j.quascirev.2011.07.006.

Madec, G., 2008: NEMO ocean engine. Note du Pole de modelisation 27, Institut Pierre-Simon Laplace, 396 pp.

McGee, D., P. B. deMenocal, G. Winckler, J. B. W. Stuut, and L. I. Bradtmiller, 2013: The magnitude, timing and abruptness of changes in North African dust deposition over the last 20,000 yr. Earth Planet. Sci. Lett., 371-372, 163-176, doi:10.1016/ j.eps1.2013.03.054.
Mulitza, S., and Coauthors, 2010: Increase in African dust flux at the onset of commercial agriculture in the Sahel region. $\mathrm{Na}$ ture, 466, 226-228, doi:10.1038/nature09213.

Muschitiello, F., Q. Zhang, H. S. Sundqvist, F. J. Davies, and H. Renssen, 2015: Arctic climate response to the termination of the African Humid Period. Quat. Sci. Rev., 125, 91-97, doi:10.1016/j.quascirev.2015.08.012.

Nicholson, S. E., 2013: The West African Sahel: A review of recent studies on the rainfall regime and its interannual variability. ISRN Meteor., 2013, 453521, doi:10.1155/2013/453521.

Patricola, C. M., and K. H. Cook, 2007: Dynamics of the West African monsoon under mid-Holocene precessional forcing: Regional climate model simulations. J. Climate, 20, 694-716, doi:10.1175/JCLI4013.1.

, and —, 2008: Atmosphere/vegetation feedbacks: A mechanism for abrupt climate change over northern Africa. J. Geophys. Res., 113, D18102, doi:10.1029/2007JD009608.

Pausata, F. S. R., G. Messori, and Q. Zhang, 2016: Impacts of dust reduction on the northward expansion of the African monsoon during the Green Sahara period. Earth Planet. Sci. Lett., 434, 298-307, doi:10.1016/j.epsl.2015.11.049.

— - K. A. Emanuel, M. Chiacchio, G. T. Diro, Q. Zhang, L. Sushama, J. C. Stager, and J. P. Donnelly, 2017a: Tropical cyclone activity enhanced by Sahara greening and reduced dust emissions during the African Humid Period. Proc. Natl. Acad. Sci. USA, 114, 6221-6226, doi:10.1073/ pnas.1619111114.

, and Coauthors, 2017b: Greening of the Sahara suppressed ENSO activity during the mid-Holocene. Nat. Commun., 8, 16020, doi:10.1038/ncomms16020.

Price, C., N. Reicher, and Y. Yair, 2015: Do West African thunderstorms predict the intensity of Atlantic hurricanes? Geophys. Res. Lett., 42, 2457-2463, doi:10.1002/2014GL062932.

Rachmayani, R., M. Prange, and M. Schulz, 2015: North African vegetation-precipitation feedback in early and mid-Holocene climate simulations with CCSM3-DGVM. Climate Past, 11, 175-185, doi:10.5194/cp-11-175-2015.

Rodríguez-Fonseca, B., and Coauthors, 2015: Variability and predictability of West African droughts: A review on the role of sea surface temperature anomalies. J. Climate, 28, 4034-4060, doi:10.1175/JCLI-D-14-00130.1.

Roehrig, R., D. Bouniol, F. Guichard, F. D. Hourdin, and J. L. Redelsperger, 2013: The present and future of the West African monsoon: A process-oriented assessment of CMIP5 simulations along the AMMA transect. J. Climate, 26, 6471-6505, doi:10.1175/JCLI-D-12-00505.1.

Rowell, D. P., 2013: Simulating SST teleconnections to Africa: What is the state of the art? J. Climate, 26, 5397-5418, doi:10.1175/JCLI-D-12-00761.1.

Schmidt, G. A., and Coauthors, 2014: Using palaeo-climate comparisons to constrain future projections in CMIP5. Climate Past, 10, 221-250, doi:10.5194/cp-10-221-2014.

Shanahan, T. M., and Coauthors, 2006: Paleoclimatic variations in West Africa from a record of late Pleistocene and Holocene lake level stands of Lake Bosumtwi, Ghana. Palaeogeogr. Palaeoclimatol. Palaeoecol., 242, 287-302, doi:10.1016/ j.palaeo.2006.06.007.

Skinner, C. B., and N. S. Diffenbaugh, 2013: The contribution of African easterly waves to monsoon precipitation in the CMIP3 ensemble. J. Geophys. Res. Atmos., 118, 3590-3609, doi:10.1002/jgrd.50363.

, and C. J. Poulsen, 2016: The role of fall season tropical plumes in enhancing Saharan rainfall during the African 
Humid Period. Geophys. Res. Lett., 43, 349-358, doi:10.1002/ 2015 GL066318.

Su, H., and J. D. Neelin, 2005: Dynamical mechanisms for African monsoon changes during the mid-Holocene. J. Geophys. Res., 110, D19105, doi:10.1029/2005JD005806.

Sultan, B., and M. Gaetani, 2016: Agriculture in West Africa in the twenty-first century: Climate change and impacts scenarios, and potential for adaptation. Front. Plant Sci., 7, 1262, doi:10.3389/fpls.2016.01262.

Swann, A. L. S., I. Y. Fung, Y. Liu, and J. C. H. Chiang, 2014: Remote vegetation feedbacks and the mid-Holocene Green Sahara. J. Climate, 27, 4857-4870, doi:10.1175/JCLI-D-13-00690.1.

Taylor, K. E., R. J. Stouffer, and G. A. Meehl, 2012: An overview of CMIP5 and the experiment design. Bull. Amer. Meteor. Soc., 93, 485-498, doi:10.1175/BAMS-D-11-00094.1.

Thorncroft, C. D., and B. J. Hoskins, 1994: An idealized study of African easterly waves. I: A linear view. Quart. J. Roy. Meteor. Soc., 120, 953-982, doi:10.1002/qj.49712051809.

_, and M. Blackburn, 1999: Maintenance of the African easterly jet. Quart. J. Roy. Meteor. Soc., 125, 763-786, doi:10.1002/ qj. 49712555502.

Tierney, J. E., F. S. R. Pausata, and P. B. deMenocal, 2017: Rainfall regimes of the Green Sahara. Sci. Adv., 3, e1601503, doi:10.1126/sciadv.1601503.
Valcke, S., 2006: OASIS3 user guide. PRISM Tech. Rep. 3, 64 pp. [Available online at http://www.prism.enes.org/Publications/ Reports/oasis3_UserGuide_T3.pdf.]

Vancoppenolle, M., T. Fichefet, H. Goosse, S. Bouillon, G. Madec, and M. A. Morales Maqueda, 2009: Simulating the mass balance and salinity of Arctic and Antarctic sea ice. 1. Model description and validation. Ocean Modell., 27, 33-53, doi:10.1016/ j.ocemod.2008.10.005.

van den Hurk, B., P. Viterbo, A. Beljaars, and A. K. Betts, 2000: Offline validation of the ERA-40 surface scheme. ECMWF Tech. Memo. 295, 42 pp.

van Hengstum, P. J., J. P. Donnelly, P. L. Fall, M. R. Toomey, N. A. Albury, and B. Kakuk, 2016: The intertropical convergence zone modulates intense hurricane strikes on the western North Atlantic margin. Sci. Rep., 6, 21728, doi:10.1038/srep21728.

Williams, R. H., and Coauthors, 2016: Glacial to Holocene changes in trans-Atlantic Saharan dust transport and dust-climate feedbacks. Sci. Adv., 2, e1600445, doi:10.1126/sciadv.1600445.

Wu, M.-L. C., O. Reale, S. D. Schubert, M. J. Suarez, R. D. Koster, and P. J. Pegion, 2009: African easterly jet: Structure and maintenance. J. Climate, 22, 4459-4480, doi:10.1175/2009JCLI2584.1.

,,,,---- and C. D. Thorncroft, 2012: African easterly jet: Barotropic instability, waves, and cyclogenesis. J. Climate, 25, 1489-1510, doi:10.1175/2011JCLI4241.1. 